\title{
A phonological reconstruction of Proto-Cerrado (Jê family) ${ }^{1}$
}

\begin{abstract}
This is the second paper in a series on the historical phonology of Macro-Jê languages. In this work, I examine the sound correspondences between the languages of the Central Jê branch, Xavánte and Xerénte, in order to arrive at a reconstruction of Proto-Central Jê. I further compare it to my reconstruction of Proto-Northern Jê (Nikulin 2016b) and propose a phonological reconstruction of Proto-Cerrado, the most recent common ancestor of Proto-Central Jê and Proto-Northern Jê. The paper also includes a non-exhaustive list of Cerrado etymologies.
\end{abstract}

Keywords: Jê languages, Macro-Jê languages, Xavánte, Xerénte, language reconstruction, comparative method

\section{Introduction}

In an earlier work (Nikulin 2016b), I have proposed a phonological reconstruction of ProtoNorthern Jê, the proto-language of the branch that comprises Apinayé, Kayapó (Mẽbêngôkre), Suyá (Kĩsêdjê), Tapayúna, Timbira and Panará languages spoken in Central Brazil. In this paper I offer a reconstruction of Proto-Cerrado (PCerr) ${ }^{2}$, the immediate ancestor of ProtoNorthern Jê (PNJ) and the proto-language of its coordinate branch, Central Jê (PCJ).

Before proceeding to the main body of this paper, some comments on my PNJ reconstruction (Nikulin 2016b) are necessary. These concern the internal phylogenetic structure of the Northern Jê branch and individual correspondences.

\subsection{Internal structure of Northern Jê}

Recent lexicostatistical investigation has shown that the Northern branch of Jê languages has the internal structure shown in Figure 1.

Figure 1. Northern Jê languages

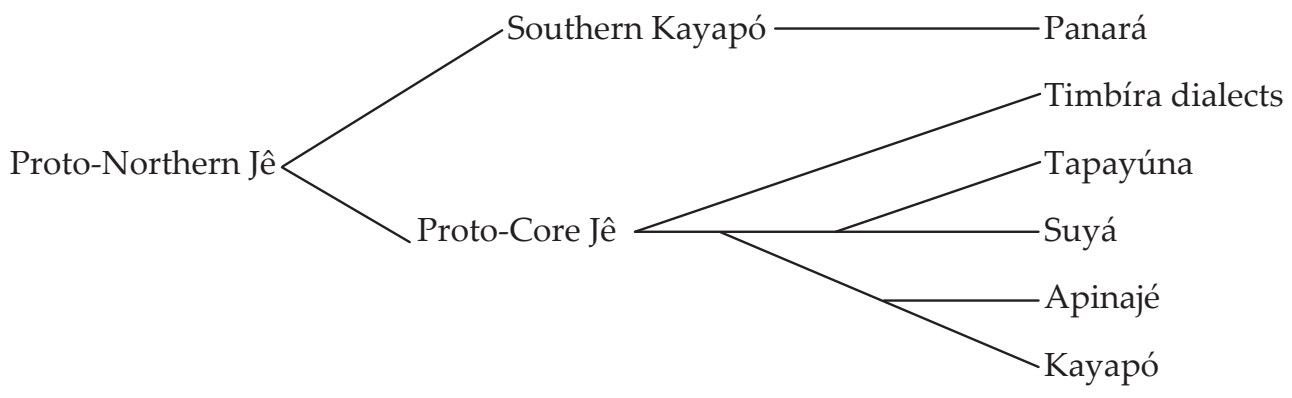

1 I am grateful to CAPES (Coordenação de Aperfeiçoamento de Pessoal de Nível Superior) for providing a scholarship to carry out the present study.

For abbreviations, transcription conventions and lexical sources, the reader is referred to Nikulin $2016 \mathrm{~b}$. The following additional abbreviations are used here: $\mathrm{DU}=$ dual, GNR = generic possessor, $\mathrm{INCL}=\mathrm{inclusive}, \mathrm{IPF}=\mathrm{im}-$ perfective, $\mathrm{NOM}=$ nominative, $\mathrm{SG}=$ singular, $\mathrm{PL}=$ plural.

${ }^{2}$ Cerrado languages have been also called Amazonian Jê (Ribeiro and Voort 2010: 549) and Northern Jê (Ramirez et al. 2015: 261) in earlier literature. 
Contrary to my earlier claims, Timbira is not likely to form a node with Apinayé and Kayapó (called AMT in Nikulin 2016b) ${ }^{3}$. Instead, it probably was the first language to split off from Proto-Core Jê. This must have occurred sometime between the III and VIII centuries CE 4 (70-82\% matches on the 110-item Swadesh wordlist). The split between Apinayé-Kayapó and Suyá-Tapayúna should be dated sometime between the VII and X centuries CE (79-86\% matches). It is also possible that Timbira, Apinayé-Kayapó and Suyá-Tapayúna diverged from each other simultaneously around $700 \mathrm{CE}$, in which case Core Jê would have a rake-like structure (cf. the working hypothesis in Nikulin 2015). The revision of the tree has been possible thanks to the inclusion of additional lexical data sources for modern languages not considered in Nikulin 2016b: Vasconcelos 2013, Bardagil-Mas 2016, Lapierre et al. 2016a (for Panará), Ham 1961, Albuquerque 2011, 2012 (for Apinayé), Camargo 2015 (for Tapayúna), DMK (for Suyá), Silva 2011, 2012 (for Pykobjê), Castro Alves 1999 (for Apãniekrá), Popjes and Popjes 1971 (for Ramkokamekrá).

The split of Northern Jê into Core Jê and Panará probably occurred sometime between the III and the V centuries BC (55-60\% matches on the 110-item Swadesh wordlist), much earlier than the split of Core Jê. This is in line with my earlier views on the internal structure of the Northern Jê branch (Nikulin 2015, 2016a, 2016b), but contrasts sharply with an alternative hypothesis, according to which Panará would form a node with Timbira, 'Savannah Jê' (Lapierre et al. 2016b, Lapierre 2017). The main argument in favor of the Savannah Jê hypothesis is that both Panará and Timbira share a non-trivial, typologically rare and seemingly unnatural sound change: the devoicing of PNJ prenasalized voiced stops $\left({ }^{* n} b,{ }^{* n} d,{ }^{* n} d_{\varphi},{ }^{* n} g\right)$. However, this sound change should be understood as part of a more general trend in Panará and Timbira historical phonologies: all PNJ voiced stops, including the oral stops ${ }^{*} b,{ }^{*} d_{\varphi},{ }^{*} g$, became voiceless in both languages (Nikulin 2016b: 171-173); no mention of this fact is made by the proponents of the Savannah Jê hypothesis. Note that, although devoicing of prenasalized stops is indeed uncommon cross-linguistically, as correctly observed by Lapierre (2017), there is nothing uncommon about the situation in which a general stop devoicing process targets stops in all environments, including the position after a nasal segment (cf. Old High German fintan 'to find', bintan 'to bind', where $t$ comes from an earlier * $d$ via the High German consonant shift). More crucially, the devoicing of voiced stops in Timbira counterfed the sound changes ${ }^{*}>h$, ${ }^{*} k>k^{h}$, unique to Timbira. This fact confirms that the voiced stop voicing in Panará and Timbira occurred independently.

\subsection{Other additions}

Major additions to my PNJ reconstruction (Nikulin 2016b) include some amendments based both on new sources and on new observations.

${ }^{3}$ The existence of this clade has also been cautiously suggested by Carvalho (2016: 70).

4 Annotated Swadesh wordlists, created within the GLD (Global Lexicostatistical Database) project, are scheduled to be available online at <http://starling.rinet.ru/new100>). Note that the Proto-Northern Jê word *ndiw $\ddot{t}$ 'new' is a probable loanword and is marked as such in the database; it was considered as a native item in the lexicostatistical calculations for Northern Jê languages.

For divergence datings, I accept the flow glottochronological model advanced by Vasilyev and Saenko (2017) and the formula proposed by the authors: $N(t)=e^{-0,61_{t}}(1+0.61 t)$, where $N(t)$ is the match percentage within the 110-item Swadesh wordlist and $t$ is the time depth of the divergence event expressed in thousands of years. The value of the loss coefficient (0.61) was calibrated on Romance material. 


\subsubsection{Panará}

New data that became available to me after the publication of my PNJ reconstruction, especially a recent article on the development of PNJ * $r$ in Panará by Carvalho (2016), challenge a number of statements that can be found in Nikulin 2016b.

1.2.1.1. PNJ * ${ }^{*}$. Most importantly, the sound law PNJ ${ }^{*} \eta r>$ PNR $y$, based on a single cog-

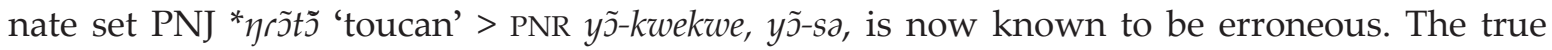
Panará reflex of this PNJ root is $i^{n} k y \tilde{\jmath}$ pepetı̆ (Andrés Salanova, p.c.). The same PNJ cluster must be reconstructed for another cognate set proposed by Carvalho (2016: 59): PNJ * $\eta \tilde{\jmath}^{2}$ 'to sprout'

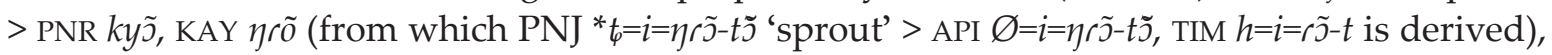
though the absence of prenasalization in Panará remains unclear. Note that PNJ ${ }^{*} \eta>P N R{ }^{n} k$ in all environments, including the position before nasalized vowels.

1.2.1.2. PNJ * $k a-$ and *a-. Another fact that I failed to mention in Nikulin $2016 \mathrm{~b}$ is that the outcomes of word-initial unstressed PNJ ${ }^{*} k a$ - and ${ }^{*} a$ - are exactly the same, suggesting a merger and a subsequent split development in the history of Panará, as shown in Figure 2.

Figure 2. The development of PNJ word-initial ${ }^{*} k a$ - and ${ }^{*} a$ - in Panará

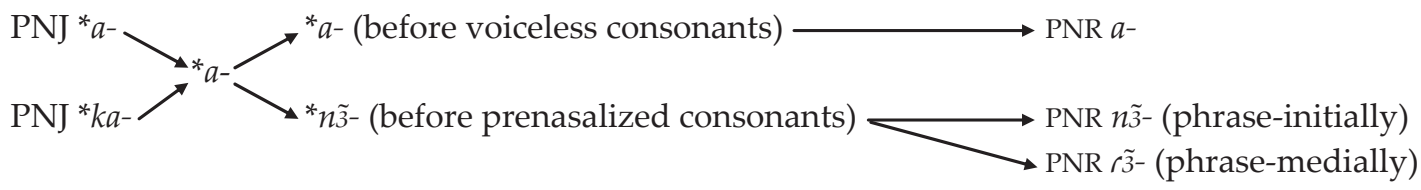

The correspondences involved in this scheme are illustrated by examples (1-2), most of which are extracted from published sources (Nikulin 2016b: 171; Carvalho 2016: 58).

(1) $\quad$ PNJ ${ }^{*} k a-$ and ${ }^{*} a->$ PNR $n \tilde{3}-/=r \tilde{3}-$

a. PNJ ${ }^{*} k a={ }^{n} g r 0$ 'warm' > PNR $n \tilde{3}=k y \jmath /=r \tilde{3}=k y \jmath$;

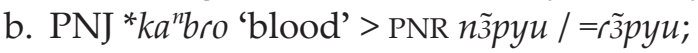

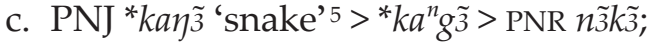

d. PNJ ${ }^{*} a^{n} g_{3}$ 'sedge seed ${ }^{\text {' }}>$ PNR $n \tilde{3}^{n} k 3$;

e. PNJ ${ }^{*} a{ }^{n}$ gro 'peccary' > PNR $n \tilde{3}^{n} k y o /=r^{n} k y o$, etc.

(2) $\quad$ PNJ ${ }^{*} k a-$ and ${ }^{*} a->$ PNR $a$ -

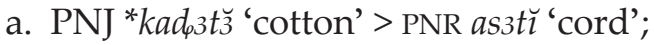

b. PNJ *katuwă *katwa 'mortar' > PNR asuă 'pestle';

c. PNJ *kaprĩ 'sad'> PNR aprĩ-pe;

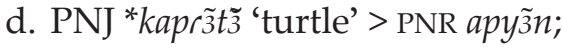

e. PNJ *akro 'vine, fishing poison' > PNR akyo, etc.

Note that Southern Kayapó wordlists capture a stage of Panará when the prothesis of $n$ had not yet occurred. For example, Barbosa (1918: 62, 81, 83) gives <a(n)kió> 'warm', <ampiô> 'blood', <anhán> 'snake', <ankiô> 'peccary'. This means that the prothesis of $n$ - and its subsequent flapping are very recent and should be dated to the XX century.

1.2.1.3. Correspondence Proto-Core Jê * $\boldsymbol{e} \sim$ Panará 3. Carvalho (2016: 60) cites two cognate sets that cannot be easily accounted for with my PNJ reconstructions. These are reproduced below in (3).

${ }^{5}$ Glossed erroneously as 'blood' in Nikulin 2016b.

${ }^{6}$ This item is of significant cultural importance for the speakers of Cerrado languages. It denotes the seeds of a plant called tiririca or capim-navalha in Portuguese, which are used for making collars. 
(3) Proto-Core Jê * $e \sim$ Panará 3

a. Proto-Core Jê * prekĕ 'tall' PNR pyz 'big, tall';

b. Proto-Core Jê *kan brekĕ 'red' PNR n $n \tilde{3}^{n} p r 3 / r \tilde{3}^{n} p r 3$.

If only these comparisons are correct, we are dealing here with a correspondence ProtoCore Jê ${ }^{*} e \sim$ Panará 3 (note that Proto-Core Jê ${ }^{*} e$ is known to correspond to Panará $e$ and ProtoCore Jê ${ }^{*} 3$ regularly corresponds to Panará 3 ). It must go back either to PNJ *e or to PNJ *3; either Proto-Core Jê or Panará must have undergone a conditioned vowel change. In order to determine the directionality of this change, external data might turn out to be useful. The word for 'red' happens to have likely cognates in Central Jê: PCJ *pre: 'red' > XAV pre:(-di), XER pre(-di), Salinas Xavánte hoy=pye, Xakriabá (Saint-Hilaire) oi=pre-de <oïpredé>, Akroá ši$k u c a=b$ ra <schikutzabrö>. PCJ ${ }^{*} \varepsilon$ is known to correspond to $\mathrm{PNJ}^{*}{ }_{3}$ (see subsection 3.2), so the vowel in Panará appears to be more archaic. However, the decision to reconstruct PNJ ${ }_{3}$ for the correspondence in question is problematic: PNJ * $r$ is known to have yielded Panará $y$ before non-front vowels (Nikulin 2016b: 170-171; Carvalho 2016: 66), which did not occur in PNR $n \tilde{3}^{n} p r 3 / r \tilde{3}^{n} p r 3$. Reconstructing a front vowel for the same correspondence would not solve the issue: in this case PNR ${ }^{*}$ prs would be expected instead of PNR pys.

The correspondence remains therefore unexplained and awaits further investigation.

\subsubsection{Apinayé and Kayapó}

In my description of the distribution of Apinayé and Kayapó reflexes of PNJ ${ }^{*} t$ (Nikulin 2016b: 172) I failed to observe that the reflex $?$ is most consistently found in PNJ stems whose initial consonant is a non-alternating ${ }^{*}$. The most salient examples are provided in (4) below.

(4) $\quad \mathrm{PNJ}{ }^{*} \phi>\mathrm{API}, \mathrm{KAY} ?$

a. PNJ * $t i$ 'bone' $>$ KAY $2 i$ (Apinayé innovated and now uses both yi and $i$ );

b. PNJ * ${ }^{*} 0$ 'leaf, a hair' > API 20, KAY 20 ;

c. PNJ *ti 'seed' > API $2 i$, KAY $2 i$;

d. PNJ * ${ }^{*} e t \breve{e} /{ }^{*} t e t$ 'to deceive' > API Reyč / Ret (but KAY et).

Note that these stems do not behave as usual class II stems in terms of Rodrigues (2012), since they suffer no modification when an internal argument expressed with a full NP immediately precedes them ${ }^{7}$. Nevertheless, their initial consonant changes to a reflex of PNJ ${ }^{*} y$ or $^{*} d$

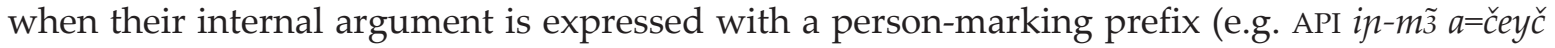

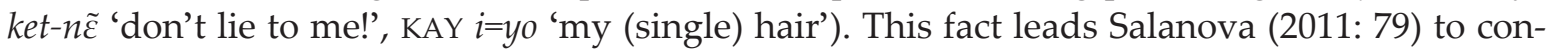
sider that these consonants are present in the underlying representation of the person-marking prefixes in these languages, arguing that in Apinayé they surface even before consonants. However, the latter observation is valid only for the first person prefix $\left(i \check{c}^{-}\right)$, but not for the second person prefix (a-). Be that as it may, the presence of these consonants in the inflected forms of the stems under consideration is likely an innovation caused by analogy with true class II stems.

\footnotetext{
7 The stems that belong to class II are expected to exhibit the following initial consonants:

$\begin{array}{ccc} & \text { PNJ } & \text { Apinayé }\end{array}$

after a person-marking prefix: $\quad{ }^{*} y,{ }^{*} d_{p} \quad \check{z}, \check{c} \quad y, \check{3}$

elsewhere (third person): $\quad *_{t} \quad \varnothing \quad \varnothing$
}

These predictions are valid both within frameworks that treat these segments as prefixes (Rodrigues 2012) and within frameworks that consider ${ }^{*} y \sim^{*} d_{4}$ and their reflexes as integral parts of roots. 


\subsubsection{Tapayúna}

Camargo (2015) offers the most complete description of Tapayúna, but this work has not been taken into consideration in my earlier research. It helps fill one of the gaps in the description of the historical phonology of Tapayúna found in Nikulin 2016b, as shown below in (5).

(5) $\quad$ PNJ ${ }^{*} g>$ TAP $k$, SUY $k$

a. PNJ *ga '2.NOM' > TAP, SUY $k a$;

b. PNJ * $g a$ 'to roast (finite)' > TAP, SUY $k a$;

c. PNJ * $g u$ '1INCL.NOM' > TAP ko, SUY $k u$.

There is one curious fact about the transcription system employed in Camargo 2015: the phonemes $m$ and $w$ recognized by the same author elsewhere (Camargo 2010) are systematically rendered as $w$, and the character $m$ is not used in the transcriptions altogether. This is not stated explicitly anywhere in the cited work. It is not entirely clear whether the correct explanation of this fact involves transcription issues or an ongoing sound change, but it must bear some relation to the apparently irregular instances of PNJ ${ }^{* n} b>$ TAP $w$, as attested by Camargo (2010). Examples of the latter are taken from (Nikulin 2016: 175) and reproduced in (6) below.

(6) $\mathrm{PNJ}{ }^{* n} b>\mathrm{TAP} w$ :

a. $\operatorname{PNJ}{ }^{*}(a=) k a^{n} b 3 t \breve{3}$ 'night' > TAP $a=g a w a r a ̆$;

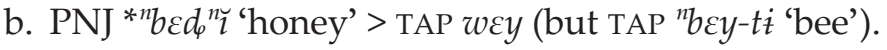

Further fieldwork on Tapayúna should clarify the issue.

Another claim in my earlier work that has been invalidated by new data referred to the impossibility of CCC-structured onsets in Tapayúna (Nikulin 2016b: 176). These are now known to be allowed, cf. Tapayúna "gswa-to 'moriche palm leaf' (although the former root is attested as "gБишӑ 'moriche palm' in isolation).

\subsection{Structure of the paper}

The remainder of this paper is organized as follows. Section 2 deals with Central Jê languages and the reconstruction of Proto-Central Jê. Onsets (subsection 2.1), syllable nuclei (subsection 2.2) and syllable-final and word-final phenomena (subsection 2.3) are tackled separately. In section 3, I compare my reconstructions of Proto-Central Jê and Proto-Northern Jê and arrive at a phonological reconstruction of Proto-Cerrado onsets (subsection 3.1), nuclei (subsection 3.2) and codas (subsection 3.3). A non-exhaustive list of Cerrado etymologies is provided in section 4 . I conclude with section 5 where I discuss the findings presented in this paper and suggest topics for future research in Cerrado historical phonology.

\section{Proto-Central Jê}

Central Jê (Akwẽ, Akuwẽ ${ }^{8}$ ) languages constitute a phylum of closely related languages formerly spoken over a vast area in Central Brazil, centered on the Tocantins watershed and reaching the headwaters of the Parnaíba and the São Francisco in the east (since 19th century, Xavánte has also been spoken as far west as the Araguaia River due to a recent expansion

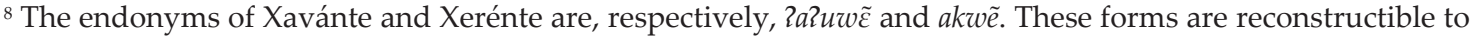
Proto-Central Jê (PCJ *akuwẽ according to the correspondences described in this section below).
} 
event). Of these, only Xavánte and Xerénte are currently spoken. Akroá, Xakriabá and the Salinas dialect of Xavánte are now extinct and their attestation is limited to short wordlists collected by Auguste de Saint-Hilaire, Wilhelm Ludwig von Eschwege, Karl Friedrich Philipp von Martius, Johann Baptist von Spix (Martius 1867) and Paul Ehrenreich (Ehrenreich 1895).

Akroá and Xakriabá wordlists have been tackled by Carvalho and Damulakis (2015), while some peculiarities of the Salinas dialect of Xavánte are discussed by Nikulin (2015: 27-29). Fragmentary nature of available data, combined with low internal diversity of the Central Jê group, makes the contribution of Akroá, Xakriabá and Salinas Xavánte data to the reconstruction of Proto-Central Jê minimal. For the most part of this subsection, only Xavánte and Xerénte data are considered below.

Xavánte and Xerénte share much of their irregular morphophonology. Phenomena like alternations and prefix substitution at the left margin of the stems, as well as nominalization via suffixing are also found in Northern Jê (and are easily projected onto Proto-Cerrado). Another phenomenon typical of Central Jê languages is the existence of special utterance-final allomorphs: a number of stems undergo drastic changes when they are preceded by a pause. These will be considered at the end of this section (2.3).

\subsection{Onset}

The correspondences between Xavánte and Xerénte onsets are rather straightforward and are exposed below in Table 1.

Table 1. Proto-Central Jê onsets and their reflexes in Xavánte and Xerénte

\begin{tabular}{|c|c|c|}
\hline PCJ & XAV & XER \\
\hline${ }^{*} \mathrm{p}$ & $\mathrm{p}$ & $\mathrm{p}$ \\
\hline${ }^{*} \mathrm{pr}$ & $\mathrm{pr}$ & $\mathrm{pr}$ \\
\hline$*_{t}$ & $\mathrm{t}$ & $\mathrm{t}$ \\
\hline${ }^{*} \mathrm{C}$ & $\mathrm{c} \sim \mathrm{s}$ & $\mathrm{S} \sim \mathrm{s}$ \\
\hline${ }^{*} \mathrm{k}$ & 3 & $\mathrm{k}$ \\
\hline${ }^{*} \mathrm{k} s$ & $3 s$ & $\mathrm{kr}$ \\
\hline${ }^{*} \mathrm{kw}$ & $3 w$ & $\mathrm{kw}$ \\
\hline${ }^{*} \mathrm{~km}$ & $3 \mathrm{~m}$ & $\mathrm{~km}$ \\
\hline${ }^{*} \mathrm{~b}$ & $\mathrm{~b}$ & $\mathrm{~b}$ \\
\hline${ }^{*} b_{c}$ & bs & bs \\
\hline$* d$ & $\mathrm{~d}$ & $\mathrm{~d}$ \\
\hline$*_{3}$ & $3 \sim z^{9}$ & $\mathrm{z} \sim \mathrm{z}, \mathrm{zd} \sim \mathrm{zd}, \mathrm{d}$ \\
\hline${ }^{*} \mathrm{~m}$ & $\mathrm{~m}$ & $\mathrm{~m}$ \\
\hline${ }^{*} \mathrm{~m} s$ & $\mathrm{~ms}$ & $\mathrm{~ms}$ \\
\hline${ }^{*} \mathrm{n}$ & $\mathrm{n}$ & $\mathrm{n}$ \\
\hline${ }^{*} \mathrm{n}$ & $\mathrm{n}^{10}$ & $\mathrm{n}$ \\
\hline
\end{tabular}

${ }^{9}$ Quintino (2000: 39,46) analyzes both / $\mathrm{z} /$ and /j/ as phonemes, stating that there is some variation between the two in oral contexts. However, this claim is not illustrated with any minimal or near-minimal pair.

${ }^{10}$ According to Quintino (2000: 39-40, 2012: 125), before back nasal vowels the allophone [n] is found instead of [n]. This phenomenon is not attested by other researchers. In fact, Pickering (2010: 63) explicitly states that in his data [j] is found both before back and front nasal vowels, noting that Quintino's data come from speakers from 


\begin{tabular}{c|c|c}
\hline PCJ & XAV & XER \\
\hline${ }^{*} \mathrm{~W}$ & $\mathrm{w}$ & $\mathrm{w}$ \\
\hline${ }^{*} \mathrm{c}$ & $\mathrm{c}$ & $\mathrm{c}$ \\
\hline${ }^{*} \mathrm{~h}$ & $\mathrm{~h}$ & $\mathrm{~h}$ \\
\hline${ }^{\circ} \varnothing$ & $?$ & $\varnothing$ \\
\hline
\end{tabular}

Note that voiced stops and nasals are in complementary distribution both in ProtoCentral Jê and in Xavánte: at least in the onset position, voiced stops occur in syllables with oral nuclei, whereas nasals occur only in syllables with nasal nuclei (McLeod 1974; Quintino 2000: 39-41, 2012: 124-125; Pickering 2010: 62, 73-77, 76-77) ${ }^{11}$. However, just like in Nikulin $2016 \mathrm{~b}$, I prefer to distinguish these allophones in my transcription. Note that the allophony in question was phonemicized in Xerénte due to syllabic reduction that eliminated some of the nuclei that had triggered the choice of the allophone in Proto-Central Jê (Mattos 1973).

Although most correspondences presented in Table 1 are trivial, several comments are in order.

\subsubsection{The reconstruction of $\mathrm{PCJ}{ }^{*} \mathrm{C}$ and ${ }^{*} 3$}

Xavánte, Akroá and Xakriabá reflexes of PCJ phonemes reconstructed here as ${ }^{*} \mathrm{C}$ and ${ }^{*} 3$ suggest that they should be reconstructed as stops or affricates rather than fricatives. The phonetic realization of the reflexes is discussed below.

McLeod (1974) describes the Xavánte reflexes as fluctuating between [ $\check{c} \sim \mathrm{c} \sim \check{\mathrm{s}} \sim \mathrm{s}$ ] and [ $\breve{3} \sim$ $3 \sim \check{z} \sim$ z] respectively, Quintino (2000: 44-45, 2012: 45) attests [c s] and [3 z] in plain speech register, while in Pickering's (2010: 63) data only fricatives ([s] and [z]) are found. According to Xavánte speaker Euzebio Prowari (apud Pickering 2010: 63), the affricates [c] and [3] are a characteristic feature of the speech of the Xavántes from the Indigenous Areas Pimentel Barbosa and Areões. I transcribe the phonemes in question as $c$ and 3 hereinafter, since affricates are more likely to represent the more archaic state than fricatives.

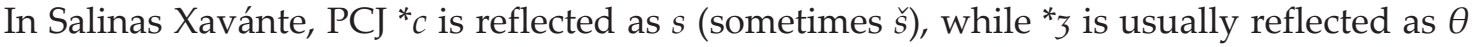
(sometimes $s$ ).

In Xerénte, PCJ palatal stops normally yielded fricatives. These fricatives are attested as retroflex [s, z] in earlier works (Mattos 1973; Krieger \& Krieger 1994: XIII-XIV; Braggio 2004: 269), but in modern Xerénte they are mostly articulated as alveolar ([s, z]) according to more recent works (Sousa Filho 2007: 73; Souza 2008: 72-74; Grannier 2009: 252; Frazão 2013: 56; Cotrim 2016: 59). It is likely that we are dealing here with a very recent sound change. I shall transcribe Xerénte fricatives as retroflex in this paper.

In some words Xerénte displays aberrant reflexes of PCJ 3 (namely, XER $z d$ or $d$ ), for which I am unable to offer an explanation. Note that these irregular reflexes often occur in variation with plain fricatives or with each other, e.g. kbazdi-kre $\sim$ kbadi-kre 'hammock', daks zaks 'to climb', dapaka zapaka 'to desire', darõtõ zarõtõ 'to jump', zawre dawer 'big', zqa da 'to stand', etc. Sousa Filho (2007: 255-256) analyzes alternating $d$ - and $z$ - as allomorphs of the same mor-

the Indigenous Area Pimentel Barbosa, whereas his own data come from residents of the community of São Marcos. For sake of simplicity, I follow McLeod (1974) and transcribe $n$.

11 Quintino (2012: 123-124) provides a minimal pair ([da-di] 'GNR-belly' vs. [na-di] 'mother-IMP'), but concludes that in the latter case the vowel of the root is underlyingly nasalized. All other researchers invariably list the form $n \tilde{a}$ 'mother'. 
pheme (the 'relational prefix' /z-/), suggesting that the occurrence of the forms with $d$ - and $z_{\text {- }}$ is not grammatically conditioned, but does not provide any explanation for the causes of the variation in question.

It is important to note that in a number of stems stem-initial PCJ ${ }^{*} \mathrm{C}$ alternated with ${ }^{*} 3$ (in oral contexts) or ${ }^{*} n$ (in nasal contexts). The ${ }^{*} c$-initial allomorph occurred only after the second person prefix ${ }^{*} a y$-, after the third person prefix ${ }^{*} \tilde{l}$ - and in third person forms without an overt prefix, as is still the case in Xerénte (Sousa Filho 2007: 247-255) and Xavánte (Estevam 2011: 138; Hall et al. 1987: 286-287). Some examples are provided in (7) below.

(7) $\quad \mathrm{PCJ}{ }^{*} 3$ and ${ }^{*} \mathrm{C}$
a. PCJ *-za'to stand' > XAV $-3 a$, XER $-z a \sim-d a$;
b. PCJ *-zadawa 'mouth' > XAV-zadawa, XER-zdawa;

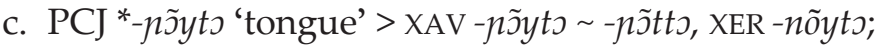
d. PCJ *ay-ca 'you stand'> XAV a-ca, XER $a y-s a$;
e. PCJ *ay-cadawa 'your mouth'> XAV a-cadawa, XER ay-sdawa;

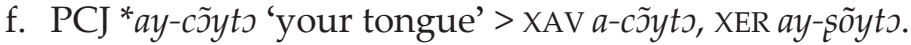

While most authors agree that the phenomenon in question can be described as a steminternal alternation, Sousa Filho (2007) considers that Xerénte - $z_{-},-d-,-n$ - and $-s$ - are separate prefixes ('relational prefixes' in the author's terms). In this work I adopt the former analysis.

In Akroá and Xakriabá, PCJ ${ }^{*} \mathrm{C}$ seems to have been reflected as s (sometimes š in Xakriabá), while PCJ ${ }^{*} 3$ appears to have yielded $\check{c}$ (sometimes $c$ in Akroá). In the latter case the data also allow for a voiced interpretation of the reflex(es) (Carvalho and Damulakis 2015: 40).

\subsubsection{Debuccalization of PCJ * $k$ in Xavánte}

It is well-known that ${ }^{*} k$ has been historically debuccalized in Xavánte, changing to $?$ (Rodrigues 1999: 178; Carvalho and Damulakis 2015: 24-26). It did not affect the Salinas dialect of Xavánte, as attested by Ehrenreich (1895), nor is it visible in the wordlists collected by Francis de Castelnau and Johann Emmanuel Pohl in the 19th century (Rodrigues 2004; Carvalho and Damulakis 2015: 25) ${ }^{12}$, suggesting that the development ${ }^{*} k>$ ? took place in the late 19th or early 20th century.

\subsubsection{The depalatalization of $\mathrm{PCJ}{ }^{*} n$ in Xerénte}

$\mathrm{PCJ}^{*} n$ (allophone of PCJ ${ }^{*} 3$ in nasal contexts) was unconditionally depalatalized to $n$ in Xerénte, thus phonemicizing the allophony reconstructible for PCJ. Note that the same process occurred independently in other Macro-Jê languages, notably in Southern Jê and in Jabutí (Ribeiro \& Voort 2010: 565-566).

\subsection{Nucleus}

The correspondences between Xerénte and Xavánte vowels are straightforward, as presented in Table 2 below.

\footnotetext{
12 Note that Rodrigues (2004: 117-118) hypothesizes that the variety attested by Castelnau and Pohl is not the direct ancestor of modern Xavánte. This assumption is needed to account for the loss of $k$ in Karajá male speech (evidenced by data from 1844), which Rodrigues attributes to Xavánte influence. If Rodrigues's hypothesis is correct, absolute dating for the sound change in question is not recoverable from historical sources.
} 
Table 2. Proto-Central Jê vowels and their reflexes in Xavánte and Xerénte.

\begin{tabular}{|c|c|c|}
\hline PCJ & XAV & XER \\
\hline *a & a & a \\
\hline$*_{\partial}$ & ә & ә \\
\hline$*_{i}$ & $\dot{\mathbf{x}}$ & $\dot{\mathrm{i}}$ \\
\hline$*_{0}$ & כ & כ \\
\hline${ }^{*} \mathrm{O}$ & o & $\mathrm{O}$ \\
\hline${ }^{*} \mathrm{u}$ & $\mathrm{u}$ & $\mathrm{u}$ \\
\hline${ }^{*} \varepsilon$ & $\varepsilon$ & $\varepsilon$ \\
\hline${ }^{*} \mathrm{e}$ & $\mathrm{e}$ & e \\
\hline$*_{i}$ & $\mathrm{i}$ & $\mathrm{i}$ \\
\hline
\end{tabular}

\begin{tabular}{|c|c|c|}
\hline PCJ & XAV & XER \\
\hline * $\tilde{\partial}$ & $\tilde{\partial}$ & $\tilde{\partial}$ \\
\hline$* \tilde{z}$ & $\tilde{\jmath}$ & $\tilde{\mathrm{O}}$ \\
\hline$* \tilde{\varepsilon}$ & $\tilde{\varepsilon}$ & $\tilde{\mathrm{e}}$ \\
\hline$*_{\tilde{1}}$ & $\tilde{\mathrm{i}}, \mathrm{i}$ & $\tilde{\mathbf{1}}$ \\
\hline
\end{tabular}

Two PCJ vowels, ${ }^{*} \dot{i}$ and ${ }^{*} 0$, were extremely rare, as are their reflexes in both languages. They are only found in a handful of words, like the postposition * 30 / * $\mathrm{CO}$ 'looking for, pursuing', the TAM marker *to, the verb *krikri 'to cry.PL' or the noun * $3 i z i k i$ // * $3 i z i \dot{i}$ 'grasshopper'. In fact, the phonemic status of $\dot{i}$ and $o$ is not recognized by Pickering (2010: 65, 163-165) for Xavánte, whereas some authors do not distinguish between Xerénte $\partial$ and $\dot{i}$ (Sousa Filho 2007: 74; Frazão 2013: 54).

A non-trivial development occurred in Xavánte: PCJ * $\tilde{i}$ was denasalized to $i$ after $c$ (for ex-

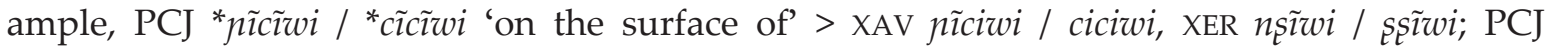
${ }^{*} k m \tilde{\partial}=c \tilde{i} c \tilde{\imath}$ 'to fill' $>\operatorname{XAV}\{m \tilde{\partial}=c i c i$, XER $k m \tilde{\partial}=s \tilde{\imath} s \tilde{l})$. For this reason, the sequence $/ c \tilde{l} /$ does not occur synchronically in Xavánte (Pickering 2010: 75, 153).

One very important, but poorly understood process that deeply affected Xerénte phonology and phonotactics consists in vowel elision (Mattos 1973; Ribeiro \& Voort 2010: 554; Frazão 2013: 85). It massively eliminated PCJ vowels under uncertain conditions (the factors possibly included stress position, consonantal environment and position within the utterance), leading to the emergence of alternating forms like ha-ra / $h-r a / h a-r$ 'to shout.NF', $k r u-k u$ / $k r-k u$ / $k r u-k$ 'to din.NF'. The distribution of these allomorphs is underdescribed and is of particular importance for the understanding of Xerénte historical phonology. Whatever might have been the original conditions for vowel elision in Xerénte, the situation observed in this language is clearly innovative when compared to Xavánte. For this reason, I assume that Xavánte syllabification can be projected onto the PCJ level.

Vowel length is contrastive in Xavánte; it has been described in autosegmental terms. Long vowels are mostly found under specific prosodic or syntactic conditions (in utterance-final allomorphs or before the particle $h \tilde{z})$, except when they arise via compensatory lengthening that accompanies the elision of $b$ before labials and $?$ (see subsection 2.3). Since nothing suggests that length contrast is innovative in Xavánte, I assume it was already present in PCJ and was lost in Xerénte.

\subsection{Coda and utterance-final allomorphs}

Xavánte allows two underlying codas: a labial coda (surface realizations include [b], [m], [p], [Ø] and lengthening of the previous vowel) and a palatal coda (surface realizations include [y], $[\varnothing]$ and lengthening of the following consonant). They are analyzed as /b/ and /z/ by Pickering (2010: 179-220) and treated as suprasegmental phenomena by Burgess (1971). 
As a consequence of massive vowel elision, Xerénte phonotactic restrictions are very different from those of Xavánte and from those that can be reconstructed for Proto-Central Jê. However, both underlying Xavánte codas have their correspondences in Xerénte. These are summarized in Table 3 below.

Table 3. Proto-Central Jê underlying codas, their surface realizations and their reflexes in Xavánte and Xerénte

\begin{tabular}{|c|c|c|c|}
\hline & PCJ & XAV & XER \\
\hline \multirow{4}{*}{$* / y /$} & \multirow{3}{*}{$*[y]$} & $y$ (before $p, b, m, w, r, h)$ & \multirow{3}{*}{$y$ (utterance-medially) $^{13}$} \\
\hline & & $y \sim$ lengthening of the following $C$ (before ?) & \\
\hline & & lengthening of the following $\mathrm{C}$ (before $t, d, n, n, c, 3$ ) & \\
\hline & $*[\varnothing]$ & $\varnothing$ (utterance-finally) & $\varnothing$ (utterance-finally) \\
\hline \multirow{6}{*}{$* / \mathrm{m} /$} & \multirow{4}{*}{${ }^{*}[\mathrm{~m}]$} & $p$ (before $t, c)$ & \multirow{4}{*}{$\begin{array}{c}m \text { (utterance-medially, } \\
\text { except before labials) }\end{array}$} \\
\hline & & $m \sim b$ (before $d, 3, r)$ & \\
\hline & & $m$ (before $n, n, h$ ) & \\
\hline & & $b \sim$ lengthening of the preceding $\mathrm{V}$ (before ?) & \\
\hline & $*[:]$ & lengthening of the preceding $\mathrm{V}$ (before labials) & \multirow{2}{*}{$\begin{array}{c}\varnothing \text { (before labials } \\
\text { and utterance-finally) }\end{array}$} \\
\hline & $*[\varnothing]$ & $\varnothing$ (utterance-finally) & \\
\hline
\end{tabular}

As is evident from Table 3 above, the coda allophony observed in Xavánte can be partly projected onto the PCJ level because it has exact correspondences in Xerénte. Namely, both in Xavánte and Xerénte both codas fail to surface in utterance-final position, and the labial coda has no consonantal realization preceding another labial consonant. Although it is possible to consider that PCJ had two underlying codas, they must have had multiple surface realizations already in PCJ. The allophony in question is exemplified in (8) below.

(8) Allophonic realizations of $\mathrm{PCJ} * /-m /$ and $* /-y /$

a. PCJ */tem/ 'new':

${ }^{*} t \varepsilon$ (utterance-finally) > XAV $t \varepsilon$, XER $t \varepsilon$;

${ }^{*} t \varepsilon m$ (utterance-medially, not before labials) > XAV tem / teb / tep, XER tem

${ }^{*} t \varepsilon$ : (before labials) > XAV te:, XER $t \varepsilon$.

b. PCJ */tãy/ 'rain':

${ }^{*} t \tilde{a}$ (utterance-finally) > XAV tã, XER tã;

${ }^{*}$ tãy (utterance-medially) > XAV tãy- / tãC-, XER tãy.

The existence of utterance-medial and utterance-final allomorphs is not specific to PCJ morphemes that end underlyingly in $* / \mathrm{m} /$ or $* / \mathrm{y} /$ or their modern Xavánte and Xerénte reflexes. This type of allomorphy is attested both in Xavánte, where it is well described (Hall et al.

${ }^{13}$ Note that in Xerénte $\partial y, \tilde{y} y$ are in free variation with $e, \tilde{e}$ (Krieger \& Krieger 1994: X). Sometimes a nasalized coda $(\tilde{y})$ is found in Xerénte; although the issue needs further investigation, I hypothesize that this happens before

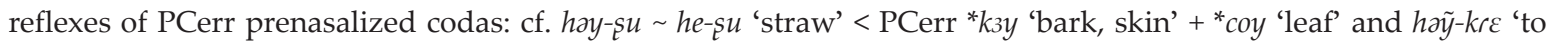

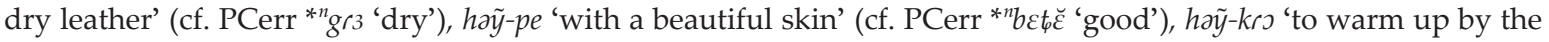
fire' (cf. PCerr ${ }^{* n} g r o$ 'to heat'). Given the cursory nature of this hypothesis, I do not reconstruct this apparent contrast to Proto-Central Jê. 
1987: 274-285; McLeod \& Mitchell 2003: 54; Estevam 2011: 139-143), and in Xerénte, where it is mentioned in passim (Siqueira 2003: 42). This allomorphy is systematized in Table 5 below; for each allomorphy class, a PCJ reconstruction is proposed.

Table 4. Allomorphy conditioned by the position within the utterance in PCJ, Xavánte and Xerénte

\begin{tabular}{|c|c|c|c|c|c|c|}
\hline \multicolumn{2}{|c|}{ PCJ } & \multirow[t]{2}{*}{ notes } & \multicolumn{2}{|c|}{ XAV } & \multicolumn{2}{|c|}{ XER } \\
\hline medial & final & & medial & final & medial & final \\
\hline \multicolumn{7}{|c|}{ Class A. The last syllable is elided in the utterance-final allomorph } \\
\hline *-VkV & $*-\mathrm{V}$ & & $-\mathrm{V} ? \mathrm{~V}$ & $-\mathrm{V}$ & $-(\mathrm{V}) \mathrm{k}(\mathrm{V})$ & $-\mathrm{V}$ \\
\hline$*-\mathrm{VbV}$ & $*-\mathrm{V}$ & $\begin{array}{l}\text { only PCJ *wakaba } \\
\text { // *waka 'price' }\end{array}$ & $-\mathrm{VbV}$ & $-\mathrm{V}$ & $-b V$ & $-\mathrm{V}$ \\
\hline$*-\mathrm{VcV}$ & $*-\mathrm{V}$ & $\begin{array}{c}\text { only PCJ *pece // } \\
\text { *pe 'good' }\end{array}$ & $-\mathrm{VcV}$ & $-\mathrm{V}$ & $-(\mathrm{V}) \mathrm{s} \mathrm{V}$ & $-\mathrm{V}$ \\
\hline
\end{tabular}

Class B. The last syllable is elided in the utterance-final allomorph; the utterance-medial allomorph is affected by nasalization ${ }^{14}$

\begin{tabular}{c|c|c|c|c|c|c}
\hline$*-\tilde{\mathrm{V}} m \tilde{\mathrm{V}}$ & $*-\mathrm{V}$ & & $-\tilde{\mathrm{V}} m \tilde{\mathrm{V}}$ & $-\mathrm{V}$ & $-(\tilde{\mathrm{V}}) m \tilde{\mathrm{V}}$ & $-\mathrm{V}$ \\
\hline$*-\tilde{\mathrm{V}} n \tilde{\mathrm{V}}$ & $*-\mathrm{V}$ & & $-\tilde{\mathrm{V}} n \tilde{\mathrm{V}}$ & $-\mathrm{V}$ & $-(\tilde{\mathrm{V}}) n \tilde{\mathrm{V}}$ & $-\mathrm{V}$ \\
\hline
\end{tabular}

Class C. PCJ *-aba //*-wa ${ }^{15}$

\begin{tabular}{c|c|c|c|c|c|c}
\hline$*-a b a$ & $*-w a$ & & $-a b a$ & $-w a$ & $-b a$ & $-w a$ \\
\hline
\end{tabular}

Class D. The vowel of the penultimate syllable is lengthened in the utterance-final allomorph, and the consonant that immediately follows it becomes voiced (unless it is already voiced)

\begin{tabular}{|c|c|c|c|c|c|c|}
\hline$*-\mathrm{V} p \mathrm{~V}$ & $*-\mathrm{V}: b \mathrm{~V}$ & oral nucleus & $-\mathrm{V} p \mathrm{~V}$ & $-\mathrm{V}: b \mathrm{~V}$ & $-(\mathrm{V}) p(\mathrm{~V})$ & $-b \mathrm{~V}$ \\
\hline $\begin{array}{l}*-\mathrm{V} t \mathrm{~V} / \\
*-\tilde{\mathrm{V}} t \tilde{\mathrm{V}}\end{array}$ & $\begin{array}{l}*-\mathrm{V}: d \mathrm{~V} / \\
*-\tilde{\mathrm{V}}: n \tilde{\mathrm{V}}\end{array}$ & $\begin{array}{c}\text { oral / nasal } \\
\text { nucleus }\end{array}$ & $-\mathrm{V} t \mathrm{~V} /-\tilde{\mathrm{V}} t \tilde{\mathrm{V}}$ & $\begin{array}{l}-\mathrm{V}: d \mathrm{~V} / \\
-\tilde{\mathrm{V}}: n \tilde{\mathrm{V}}\end{array}$ & $\begin{array}{l}-(\mathrm{V}) t(\mathrm{~V}) / \\
-(\tilde{\mathrm{V}}) t(\tilde{\mathrm{V}})\end{array}$ & $-d \mathrm{~V} /-n \tilde{\mathrm{V}}$ \\
\hline $\begin{array}{l}*_{-} \mathrm{V} d \mathrm{~V} / \\
*_{-} \tilde{\mathrm{V}} n \tilde{\mathrm{V}}\end{array}$ & $\begin{array}{l}{ }^{*}-\mathrm{V}: d \mathrm{~V} / \\
*-\tilde{\mathrm{V}}: n \tilde{\mathrm{V}}\end{array}$ & $\begin{array}{c}\text { oral / nasal } \\
\text { nucleus }\end{array}$ & $-\mathrm{V} d \mathrm{~V} /-\tilde{\mathrm{V}} n \tilde{\mathrm{V}}$ & $\begin{array}{l}-\mathrm{V}: d \mathrm{~V} / \\
-\tilde{\mathrm{V}}: n \tilde{\mathrm{V}}\end{array}$ & \multirow{3}{*}{\multicolumn{2}{|c|}{ no alternations }} \\
\hline${ }^{*}-\mathrm{V} r \mathrm{~V}$ & *-V:sV & & $-\mathrm{V} r \mathrm{~V}$ & $-\mathrm{V}: r \mathrm{~V}$ & & \\
\hline $\begin{array}{l}{ }^{*}-\mathrm{V} b(r) \mathrm{V} / \\
{ }^{*}-\tilde{\mathrm{V}} m(\varsigma) \tilde{\mathrm{V}}\end{array}$ & $\begin{array}{l}{ }^{*}-\mathrm{V}: b(r) \mathrm{V} / \\
{ }^{*}-\tilde{\mathrm{V}}: m(r) \tilde{\mathrm{V}}\end{array}$ & $\begin{array}{c}\text { oral / nasal } \\
\text { nucleus }\end{array}$ & $\begin{array}{l}-\mathrm{V} b(r) \mathrm{V} / \\
-\tilde{\mathrm{V}} m(r) \tilde{\mathrm{V}}\end{array}$ & $\begin{array}{l}-\mathrm{V}: b(r) \mathrm{V} / \\
-\tilde{\mathrm{V}}: m(r) \tilde{\mathrm{V}}\end{array}$ & & \\
\hline
\end{tabular}

Class E. The final vowel is long in the utterance-medial allomorph but short in the utterance-final allomorph

\begin{tabular}{l|l|l|l|l|l}
$*-\mathrm{V}:$ & $*-\mathrm{V}$ & oral nucleus & $-\mathrm{V}:$ & $-\mathrm{V}$ & no alternations \\
\hline
\end{tabular}

Notes. (1) The notation $-V C V(-V p V,-V \imath V, \ldots)$ presupposes that the vowels that flank the consonant are identical. (2) $\tilde{V}$ stands for nasal vowels. V stands for any vowel (oral or nasal), unless it is found to the left of a slash (like in * $\left.-V t V /{ }^{*}-\tilde{V} t \tilde{V}\right)$, in which case it stands for an oral vowel.

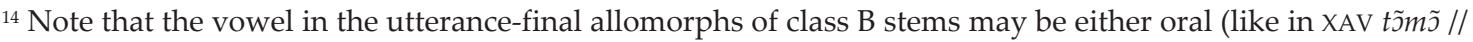
to 'eye') or nasal (like in XAV mĩmi // mĩ 'firewood'). In the former case the nasality of the vowel predictably affects

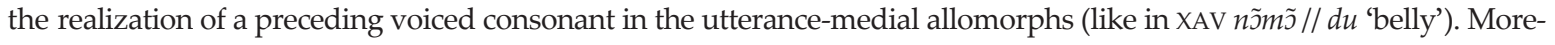
over, in all Central Jê languages the inventory of nasal vowels is smaller than that of oral vowels, and for this reason multiple vowels found in utterance-final allomorphs may correspond to one and the same vowel in utterance-

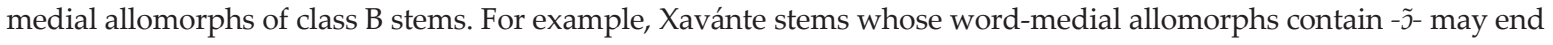

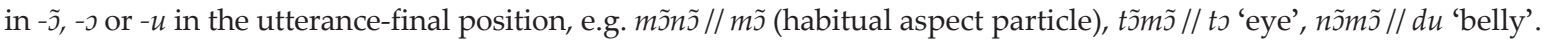

15 The alternation - $a b a / /-w a$ may affect the realization of the preceding segment in Xavánte (and presumably also in PCJ). For example, in XAV mãprebaba // mãpre:wa 'father-in-law, mother-in-law' underlying /m/ is predictably realized as [b] before - $a b a$, but as vowel length before the labial consonant - $w$ (this is described in the subsection above). 
A minimal number of exceptions to these generalizations is found. In the Xavánte reflex of PCJ *nĩp=tete // *nĩp=te:de 'to be strong' (XAV nĩp=tete/ap=tete // nĩp=te:te/ap=te:te 'to get strong, to make an effort, to recover'), the medial consonant does not undergo voicing in the utterancefinal allomorph, as expected; however, the Xerénte reflex is regular (cf. XER nĩp=tete nĩp=tte nĩ $=$ tet // nĩp=tde). In PCJ *pati // *pa:di 'southern tamandua' (XAV pati // pa:di, XER padi, pat-re), unlike in other class D stems, the vowels flanking the alternating consonant are not identical.

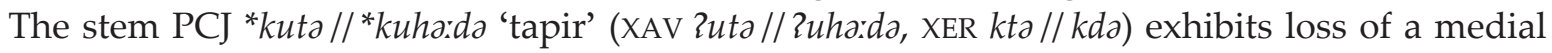
syllable in the utterance-medial allomorph (PCJ ${ }^{* *} k$ hhata would be expected).

Although I do not make an attempt at postulating a morphophonemic analysis for each class of the allomorphy, it is tempting to consider that the final vowels of the stems of classes $\mathrm{A}, \mathrm{B}$ and $\mathrm{D}$ are absent from their underlying representation, since their quality is entirely predictable: they are always a copy of the vowel of the penultimate syllable ${ }^{16}$. This fact allows for a rhyme treatment of the bisyllabic sequences participating in the alternations; for example,

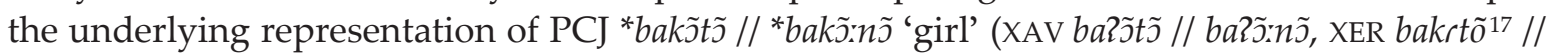
baknõ) would include the rhyme*/-̃̃t/ and the coda*/-t/.

In the remainder of this paper I will use segmental reconstruction for the alternating stems, despite being aware that it is possible to posit morphophonemic rules accounting for the allomorphy.

\section{Proto-Cerrado}

Now that phonological reconstructions are available for Proto-Northern Jê and Proto-Central Jê, it is possible to assess the reconstruction of Proto-Cerrado. Onsets, syllable nuclei and codas will be tackled separately.

\subsection{Onset}

An allophonic process targeting underlying nasal consonants is reconstructed by me for ProtoNorthern Jê. It triggers the surface realization of underlying nasal consonants $* / m /, * / n /$, $* / n /$ and $* / \eta /$ as prenasalized voiced obstruents $\left({ }^{* n} b,{ }^{* n} d,{ }^{* n} d_{,},{ }^{* n} g\right.$ ) in oral contexts (as defined by the nasality of the nucleus). It is important to note that an essentially identical process is attested in Macro-Jê languages beyond the Cerrado branch (see D’Angelis 1998 for Kaingáng, Pessoa 2012 for Krenák and Voort 2007: 138 for Arikapú) ${ }^{18}$ and thus must go back to ProtoMacro-Jê.

The correspondences between Proto-Northern Jê and Proto-Central Jê onsets, as well as the proposed Proto-Cerrado reconstructions for these correspondences, are exposed below in Table 5.

As is evident from the table, Proto-Northern Jê faithfully retains the contrasts that existed in Proto-Cerrado. The only innovation that I posit for the history of Proto-Northern Jê onsets is the fortition of PCerr * $w$ (in all environments) and * $y$ (in stressed syllables), as exemplified in (8) below.

${ }^{16}$ Note that this phenomenon is highly reminiscent of Proto-Northern Jê echo vowels (Nikulin 2016b: 168$168,182-183)$.

17 The variation $k t \sim k r t, k d \sim k r d$ is widely attested in Xerénte (see Frazão 2013: 46).

${ }^{18}$ An Optimality Theory account of the prenasalized consonants in Macro-Jê languages is offered by Damulakis (2010). Voort's analysis of Arikapú phonology is challenged by Ribeiro (2008). 
Table 5. Proto-Cerrado onsets and their reflexes in Proto-Northern Jê and Proto-Central Jê.

\begin{tabular}{|c|c|c|c|c|c|c|}
\hline \multicolumn{2}{|c|}{ PCerr } & \multicolumn{2}{|c|}{ PNJ } & \multicolumn{3}{|c|}{ PCJ } \\
\hline $\begin{array}{c}\text { before } \\
\text { oral } \\
\text { vowels }\end{array}$ & $\begin{array}{c}\text { before } \\
\text { nasal } \\
\text { vowels }\end{array}$ & $\begin{array}{c}\text { before oral } \\
\text { vowels }\end{array}$ & $\begin{array}{c}\text { before } \\
\text { nasal } \\
\text { vowels }\end{array}$ & $\begin{array}{l}\text { before PCerr } \\
\text { oral non-high } \\
\text { vowels }\end{array}$ & $\begin{array}{c}\text { before PCerr } \\
\text { oral high } \\
\text { vowels }\end{array}$ & $\begin{array}{c}\text { before } \\
\text { PCerr nasal } \\
\text { vowels }\end{array}$ \\
\hline \multicolumn{2}{|c|}{${ }^{*} p(r)$} & \multicolumn{2}{|c|}{${ }^{*} p(r)$} & \multirow{2}{*}{${ }^{*} p(r)$} & \multirow{2}{*}{$* b(r)$} & \multirow{2}{*}{${ }^{*} m(r)$} \\
\hline${ }^{* \mathrm{n}} b(r)$ & ${ }^{*} m(r)$ & ${ }^{* n} b(r)$ & ${ }^{*} m(r)$ & & & \\
\hline \multicolumn{2}{|c|}{${ }^{*} t$} & \multicolumn{2}{|c|}{${ }^{*} t$} & \multirow{2}{*}{${ }^{*} t$} & \multirow{2}{*}{${ }^{*} d$} & \multirow{2}{*}{${ }^{*} n$} \\
\hline${ }^{* \mathrm{n}} d$ & ${ }^{*} n$ & ${ }^{* n} d$ & ${ }^{*} n$ & & & \\
\hline \multicolumn{2}{|c|}{$*_{\phi}$} & \multicolumn{2}{|c|}{${ }^{*} \phi$} & \multirow{2}{*}{${ }^{*} \mathrm{C}$} & ${ }^{*} 3,{ }^{*} h^{+}$ & \multirow{3}{*}{${ }^{*} n$} \\
\hline${ }^{* n} d_{p}$ & \multirow{2}{*}{${ }^{*} n$} & ${ }^{* n} d$ & \multirow{2}{*}{${ }^{*} n$} & & N/A & \\
\hline${ }^{*} y$ & & ${ }^{*} y_{,}{ }^{*} d_{\varphi^{*}}$ & & $*_{3}$ & ${ }^{*} 3,{ }^{*} c^{\S}$ & \\
\hline \multicolumn{2}{|c|}{$* k(r)$} & \multicolumn{2}{|c|}{${ }^{*} k(r)$} & \multirow{3}{*}{\multicolumn{2}{|c|}{${ }^{*} k(r),{ }^{*} h,{ }^{*} w^{\mathbb{I}}$}} & ${ }^{*} k(r)$ \\
\hline${ }^{* n} g(r)$ & \multirow{2}{*}{${ }^{*} \eta(r)$} & ${ }^{* n} g(r)$ & \multirow{2}{*}{$* \eta(r)$} & & & \multirow{2}{*}{$\mathrm{N} / \mathrm{A}$} \\
\hline${ }^{*} g$ & & $*^{*} g$ & & & & \\
\hline \multicolumn{2}{|c|}{$* w$} & \multicolumn{2}{|c|}{$* b$} & \multicolumn{3}{|c|}{${ }^{*} w$} \\
\hline \multicolumn{2}{|c|}{${ }^{*} r$} & \multicolumn{2}{|c|}{${ }^{*} r$} & \multicolumn{3}{|c|}{${ }^{*} r$} \\
\hline \multicolumn{2}{|c|}{$* \varnothing$} & \multicolumn{2}{|c|}{$\star \varnothing$} & \multicolumn{3}{|c|}{$\star \varnothing$} \\
\hline
\end{tabular}

$\dagger{ }^{*} h$ before ${ }^{*} i,{ }^{*} z$ elsewhere. $\ddagger^{*} d_{0}$ in stressed syllables, ${ }^{*} y$ in unstressed syllables. $\S{ }^{*} c$ before ${ }^{*} i,{ }^{*} z$ elsewhere. II PCerr ${ }^{*} k_{3},{ }^{* n} g_{3},{ }^{*} k(r) \dot{i},{ }^{* n} g(r) \dot{i}>$ PCJ *ho; PCerr ${ }^{*} k a->$ PCJ *wa:- (in initial unstressed syllables).

(8) Fortition in Proto-Northern Jê

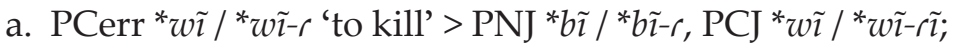

b. PCerr *wa 'I'> PNJ *ba, PCJ *wa;

c. PCerr *weke 'partridge' > PNJ *beke, PCJ *wiki;

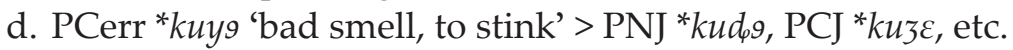

Note that Proto-Northern Jê has both ${ }^{*} w$ and ${ }^{*} y$ in stressed syllables, but only in words

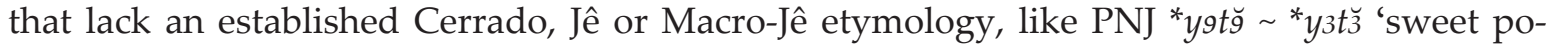
tato', *wewe 'butterfly'. These may be explained away as borrowings from an unknown source or attributed to a substrate North Amazonian language, whose existence is corroborated by certain lexical similarities between Proto-Northern Jê, Nadahup and Yanomami languages (Nikulin \& Carvalho 2017: 38).

Proto-Central Jê appears to be much less conservative than Proto-Northern Jê. The most important change that affected its onsets was the merger of voiceless and voiced occlusive consonants; it is described in more detail in subsection 3.1.1 below. Other conditioned sound changes are tackled in subsections 3.1.2-5.

\subsubsection{Occlusive merger}

The merger of Proto-Cerrado voiceless and voiced occlusives rearranged the distribution of most of the onsets. PCerr ${ }^{*} k$ and ${ }^{*} g$ normally yield PCJ ${ }^{*} k$ in all contexts, as shown in (9) below. 
(9) Occlusive merger in velars

a. PCerr *kakă 'to cough' > PNJ *kakŭ, PCJ *kaka;

b. PCerr ${ }^{*} k r a$ 'offspring' $>$ PNJ ${ }^{*} k r a$, PCJ ${ }^{*} k r a: / /{ }^{*} k r a$;

c. PCerr ${ }^{*} k \tilde{\varepsilon} t \tilde{\varepsilon}$ 'stone' > PNJ ${ }^{*} k \tilde{\varepsilon} n \tilde{\varepsilon}, \operatorname{PCJ}{ }^{*} k \tilde{\varepsilon} t \tilde{\varepsilon} / /{ }^{*} k \tilde{\varepsilon}: n \tilde{\varepsilon}$;

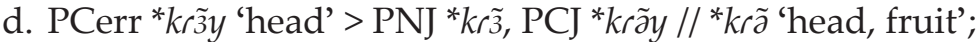

e. PCerr ${ }^{*} k r \tilde{\varepsilon}$ 'parakeet' $>$ PNJ ${ }^{*} k r \tilde{\varepsilon}$, PCJ ${ }^{*} k r \tilde{\varepsilon}$;

f. PCerr ${ }^{*} k r \tilde{\varepsilon} /{ }^{*} k r \tilde{\varepsilon}-r \sim{ }^{*} k r \tilde{\varepsilon}-n \tilde{\varepsilon}$ ' to eat' $>$ PNJ ${ }^{*} k r \tilde{\varepsilon} /{ }^{*} k r \tilde{\varepsilon}-r$, PCJ ${ }^{*} k r \tilde{\varepsilon} /{ }^{*} k r \tilde{\varepsilon}-n \tilde{\varepsilon}$;

g. PCerr *kutimü 'fire' > PNJ *kuti, PCJ *kunãmã // *kuca;

h. PCerr ${ }^{* n} g o y$ 'water' > PNJ ${ }^{* n} g o(t-), P C J{ }^{*} k u y / /{ }^{*} k u$ 'still water';

i. PCerr ${ }^{* n} g r 3$ 'dry' $>$ PNJ ${ }^{* n} g r 3, P C J{ }^{*} k r \varepsilon$;

j. PCerr ${ }^{* n} g r \varepsilon$ 'egg' $>$ PNJ ${ }^{* n} g r \varepsilon$, PCJ *kre 'egg', etc.

As for PCerr labial and coronal obstruents, reflexes vary. Before nasal nuclei, both voiceless and voiced occlusives yielded nasal consonants (10).

(10) Occlusive merger in labials and coronals before PCerr nasal nuclei

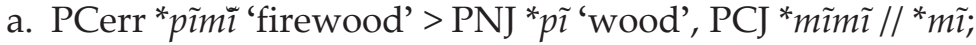

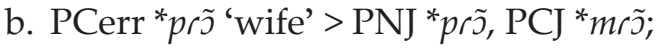

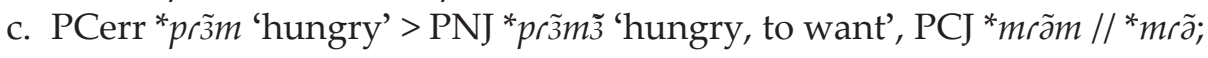

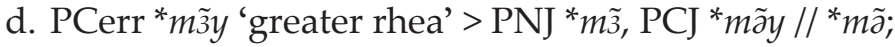

e. PCerr ${ }^{*} m \tilde{\varepsilon} y$ 'to throw.SG' > PNJ ${ }^{*} m \tilde{\varepsilon} /{ }^{*} m \tilde{\varepsilon}-n, \mathrm{PCJ}{ }^{*} m \tilde{\varepsilon} y / /{ }^{*} m \tilde{\varepsilon}$;

f. PCerr ${ }^{*} t \tilde{\varepsilon} /{ }^{*} t \tilde{\varepsilon}-m$ 'to go.SG'> PNJ ${ }^{*} t \tilde{\varepsilon} /{ }^{*} t \tilde{\varepsilon}-m$, PCJ ${ }^{*} n \tilde{\varepsilon}-m / /{ }^{*} n \tilde{\varepsilon}$ 'to go.DU';

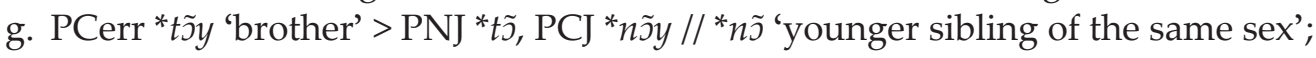

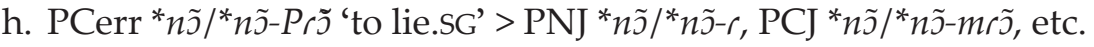

Before Proto-Cerrado high oral nuclei, voiced obstruent reflexes are found (11).

(11) Occlusive merger in labials and coronals before PCerr high nuclei

a. PCerr *purŭ 'field' > PNJ *purŭ, PCJ *buru // *burcu;

b. PCerr * pizy 'achiote' > PNJ *pi, PCJ *bay // *bo;

c. PCerr *nbutŭ 'neck' > PNJ *nbutŭ, PCJ *butu // ${ }^{*} b u: d u$;

d. PCerr *"bittu 'sun' > PNJ *nbitü, PCJ *bata // *ba:da;

e. PCerr *"binü 'tail, penis' > PNJ *nbi, PCJ *mãnã // *ba;

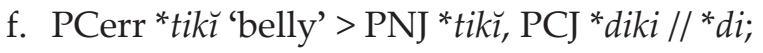

g. PCerr *tu/*tu-r 'to carry' > PNJ *tu/*tu-r, PCJ *du//*du-ri;

h. PCerr *tumŭ 'belly' > PNJ *tu, PCJ *ñ̃m $/ /{ }^{*} d u$, etc.

Before other Proto-Cerrado oral nuclei, voiceless obstruents are the regular outcome (12).

(12) Occlusive merger in labials and coronals before PCerr non-high nuclei

a. PCerr *kupe 'to touch, to move' > PNJ *kupe, PCJ *kupi;

b. PCerr *pară 'foot' > PNJ *parı̆, PCJ *para // *para;

c. PCerr ${ }^{* n} b a$ 'liver' > PNJ *nba, PCJ * $p a$;

d. PCerr *nbro 'ashes' > PNJ *nbro, PCJ *pro 'powder, foam';

e. PCerr *kan broy 'blood' > PNJ *kan bro, PCJ *wa:pruy // *wa:pru;

f. PCerr *terĕ 'fruit of a k. of palm' > PNJ *terĕ, PCJ *tiri // *tirri 'bacuri coconut';

g. PCerr ${ }^{*} t e$ 'tick' $>$ PNJ ${ }^{*} t e, P C J{ }^{*} t i$;

h. PCerr ${ }^{*} t 3 b^{n}$ 'new' $>$ PNJ ${ }^{*} t_{3} b^{n}{ }_{l}$ 'raw', PCJ ${ }^{*} t \varepsilon m / /{ }^{*} t \varepsilon$;

i. PCerr ${ }^{*} t \varepsilon p \breve{\varepsilon}$ ' fish' > PNJ ${ }^{*} t \varepsilon p \breve{\varepsilon}$, PCJ ${ }^{*}$ tepe // *te:be;

j. PCerr ${ }^{*} n \tilde{y} y$ to 'tongue' > PNJ *ñ̃to, PCJ * $n \tilde{\partial} y t s ;$

k. PCerr $\left.{ }^{* n} d\right\lrcorner m \breve{s}$ 'eye' $>$ PNJ $\left.{ }^{* n} d\right\lrcorner(p-)$, PCJ ${ }^{*} t \tilde{\jmath} m \tilde{\jmath} /{ }^{*}$ ts, etc. 
Note that the process described in this subsection occurred prior to the raising of ProtoCerrado mid-high vowels in Central Jê (PCerr ${ }^{*} e>$ PCJ ${ }^{*} i$, PCerr ${ }^{*} o>$ PCJ ${ }^{*} u$ ) and prior to the lowering of PCerr ${ }^{*} i>\mathrm{PCJ}{ }^{*}$. That way, the contrast between Proto-Cerrado syllables like ${ }^{*} t e$ and ${ }^{*} t i$ survives in Proto-Central Jê as ${ }^{*} t i$ and ${ }^{*} d i$ (cf. $11 \mathrm{f}$ and $12 \mathrm{f}-\mathrm{g}$ ).

The situation with Proto-Cerrado palatal occlusives is slightly more complicated. Many Proto-Cerrado inflectable stems are subject to the alternation of their initial consonant: their uninflected form features a stem-initial ${ }^{*} y$ - $\left({ }^{*} n\right.$ - before nasal vowels) and their third person form starts with a ${ }^{*} t$-, cf. PCerr ${ }^{*} y w a$ 'tooth' (third person ${ }^{*} t w a$ ), PCerr ${ }^{*} n \tilde{y} y t o$ 'tongue' (third person ${ }^{*} t \tilde{\jmath} y$ to). It is likely that alternating PCerr ${ }^{*} t^{-}$and ${ }^{*} y-\left.\right|^{*} n$ - remain distinct in Central Jê

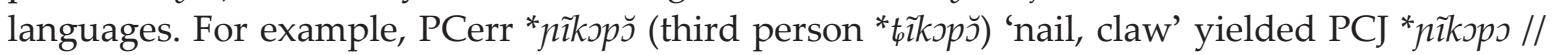
*nîks:bs, which appears as *-ciksps // *-ciks:bs after the prefixes *ay- (second person) and * ${ }^{*}$ (third person). If PCJ allomorphs do reflect PCerr uninflected form and third person form respectively, the merger of palatal occlusives in PCJ has to be considered incomplete.

However, the Central Jê reflexes of non-alternating PCerr ${ }^{*} t$, as well as of its voiced coun-

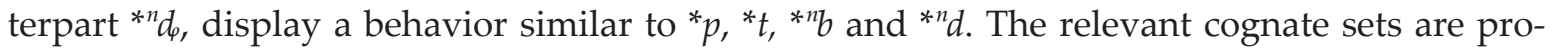
vided in (13) below.

(13) Merger of PCerr palatal occlusives

a. PCerr ${ }^{*}{ }_{t} y$ 'leaf, a hair' $>$ PNJ ${ }^{*}{ }_{\varphi}, \mathrm{PCJ}{ }^{*} \mathrm{cuy} / /{ }^{*} \mathrm{cu}$;

b. PCerr *yate 'nest' > PNJ *yate, PCJ *zaci;

c. PCerr ${ }^{*} k a^{n} d_{\varphi} e$ 'star' > PNJ *kan $d_{\varphi} e, \mathrm{PCJ}{ }^{*} w a: c i$;

d. PCerr ${ }^{* n} d_{\phi} a /{ }^{* n} d_{\varphi} a-r$ 'to bite' $>$ PNJ ${ }^{* n} d_{\phi} a /{ }^{* n} d_{\phi} a-r$, PCJ ${ }^{*} c a /{ }^{*} c a-r i$;

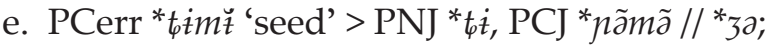

f. PCerr ${ }^{*} k u t i m \ddot{t}$ 'fire' > PNJ *kutit, PCJ *kunãmã // ${ }^{*} k u z a ;$

g. PCerr ${ }^{*} t \tilde{\imath}$ 'meat' $>$ PNJ ${ }^{*} t \tilde{\imath}$, PCJ ${ }^{*} n \tilde{i}$.

The following distribution is found in Proto-Central Jê: a voiceless reflex $\left(\mathrm{PCJ}{ }^{*} \mathrm{c}\right)$ is found before PCerr non-high oral vowels $(13 \mathrm{a}-\mathrm{d})$, a voiced reflex $\left(\mathrm{PCJ}^{*}\right.$ ) is found before PCerr high oral vowels (13e-f), and a nasal reflex $\left(\mathrm{PCJ}^{*} n\right)$ occurs preceding a nasal vowel (13g). A more profound investigation of Central Jê historical morphology should shed light on the details of the operation of the occlusive merger at the palatal point of articulation.

\subsubsection{PCerr ${ }^{*} k a->\mathrm{PCJ}^{*} w a:-$}

As has already been noted by Davis (1966: 14), PCerr ${ }^{*} k a$ - yielded PCJ *wa:- in unstressed (nonfinal) syllables (Davis erroneously states that the condition for this sound change is the wordinitial position, but in reality it fails to occur in monosyllabic words, like PCerr *kakă 'to cough' $>$ PCJ *kaka). Some examples are provided in (14).

(14) PCerr *ka- > PCJ *wa:-

a. PCerr *kan broy 'blood' > PNJ *kan bro, PCJ *wa:pruy // *wa:pru;

b. PCerr ${ }^{*} k a^{n} d_{\varphi} e$ 'star'> PNJ *kan $d_{\varphi} e$, PCJ *wa:ci;

c. PCerr ${ }^{*} k a={ }^{n} g r o$ 'hot' $>$ PNJ ${ }^{*} k a={ }^{n} g r o$, PCJ ${ }^{*} w a:=k r o$;

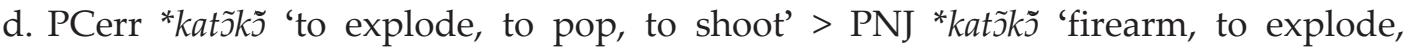
to pop', PCJ *wañ̃ k̃̃ 'to explode, to attack';

e. PCerr ${ }^{*} k a^{n} g a$ 'lazy' > PNJ * $k a^{n} g a$, PCJ ${ }^{*} w a: k a$;

f. PCerr ${ }^{*} k a r \tilde{\jmath}$ 'shadow, spirit' > PNJ ${ }^{*} k a r \tilde{\jmath}, \mathrm{PCJ}{ }^{*}$ war $r \tilde{z}$, etc. 
It is probable that PCerr ${ }^{*} k$ was articulated as ${ }^{*}[g]$ in unstressed syllables, at least before ${ }^{*} a$; this allophonic realization is attested synchronically in Apinayé and Tapayúna. Panará also seems to retain its traces (Nikulin 2016b: 171, 176). Carvalho (2016: 70) observed that "[t]hough one might claim that the outcomes of the Panará and Central Jê developments are only tenuously similar, the conditioning environment is identical for both and seems interestingly unusual”, suggesting tentatively that this might be an innovation shared by Panará and Central Jê. Given that other data support the inclusion of Panará into Northern Jê, ruling out the possibility of a node consisting of Central Jê and Panará, I am inclined to envision these facts as direct traces of a Proto-Cerrado allophony.

\subsubsection{PCerr ${ }^{*} t i>\mathrm{PCJ}{ }^{*} h i$, PCerr ${ }^{*} y i>\mathrm{PCJ}{ }^{*} c i$}

Certain developments of PCerr palatals before ${ }^{*} i$ are evident in the cognate sets listed in (15) below.

(15) $\quad$ PCerr ${ }^{*} t i>\mathrm{PCJ}{ }^{*} h i, \mathrm{PCerr}{ }^{*} y i>\mathrm{PCJ}{ }^{*} c i$

a. PCerr ${ }^{*} t i$ 'bone' $>$ PNJ ${ }^{*} t i, \mathrm{PCJ}{ }^{*} h i$;

b. PCerr ${ }^{*} y i /{ }^{*} y i-r\left(3\right.$ person $\left.{ }^{*} t i /{ }^{*} t i-r\right)$ 'to put, to lay' $>$ PNJ ${ }^{*} d_{\phi} i{ }^{*} d_{\varphi} i-r \breve{l}\left(3\right.$ person $\left.{ }^{*} t i{ }^{*} t i-r \breve{l}\right)$, $\mathrm{PCJ}{ }^{*} h i /{ }^{*} h i-r i$;

c. PCerr *nĩyi 'name' > PNJ *nĩdi, PCJ *nĩci // *nĩ:ci;

d. PCerr *piyi * pĩyi 'one'> PNJ *pid $i$, PCJ *mĩci.

However, details of this development are still poorly understood. For instance, it is unclear why the third person form of the verb 'to put, to lay' (15b) was generalized in Central Jê.

$$
\text { 3.1.4. PCerr }{ }^{*} k(r) \dot{i},{ }^{*} g(r) \dot{i},{ }^{*} k 3,{ }^{* n} g_{3}>\mathrm{PCJ}{ }^{*} h a
$$

Davis (1966: 14) already noted that Proto-Jê ${ }^{*} k$ and ${ }^{*} k r$ are reflected as Xavánte $h$ before $\partial$. However, it is now evident that the change ${ }^{*} k(r)>{ }^{*} h$ was fed by the occlusive merger: PCerr ${ }^{*} k$ and ${ }^{* n} g$ behave identically in this respect. The data presented in (16) below exemplify the merger of ${ }^{*} k r i$ and ${ }^{* n} g r i,{ }^{*} k 3$ and ${ }^{* n} g 3$.

(16) PCerr ${ }^{*} k s i,{ }^{* n} g_{s i},{ }^{*} k_{3},{ }^{* n}{ }^{3}>\mathrm{PCJ}{ }^{*} h \partial$

a. PCerr ${ }^{*} k s i$ 'cold' $>$ PNJ ${ }^{*} k s i$, PCJ ${ }^{*} h$;

b. PCerr *kukritü 'tapir' > PNJ *kukritü, PCJ *kuta // *kuha:da;

c. PCerr *kritŭ 'flint, firestone; metal' > PNJ *kritü, PCJ *hata // *ha:do;

d. PCerr ${ }^{* n}$ grikü 'angry, upset' > PNJ *ngrikt̆, PCJ *haka;

e. PCerr *k3y 'skin, bark, breast' > PNJ *k3, PCJ *hay;

f. PCerr ${ }^{*} k_{3} /{ }^{*} k_{3}-r$ 'to shout' $>$ PNJ ${ }^{*} k_{3} /{ }^{*} k_{3}-r, \mathrm{PCJ}{ }^{*} h a /{ }^{*} h a-r \partial$;

g. PCerr *ngz 'men's house' > PNJ *ng3 'men's house, courtyard', PCJ *ha 'young men's house', etc.

The development of PCerr ${ }^{*} k \dot{i}$ and ${ }^{*}{ }^{n} g i$ in Central Jê is less clear due to the scarcity of relevant data. One possible cognate set that suggests that PCerr ${ }^{*} k \dot{i}>$ PCJ ${ }^{*} h a$ involves the correspondence of Proto-Southern Jê *yãd=ki 'mouth' to Xavánte zay=ha 'lip, mouth' and probably Xerénte zay=ho 'buttocks' (< PCJ *3ay=ho); no Northern Jê cognate is available. If these words are indeed cognate, they must go back to a Proto-Jê stem ending in * $=k \dot{i}$.

Note that PCerr ${ }^{*} k r 3$ and ${ }^{* n} g r 3$ must have developed normally, cf. PCerr ${ }^{* n} g r 3$ 'dry' > $\mathrm{PNJ}{ }^{* n} g r 3, \mathrm{PCJ}{ }^{*} k r \varepsilon$. 


\subsubsection{Interaction with medials}

It appears that Proto-Cerrado had a system of rising diphthongs, just like Proto-Northern Jê. In some cases Proto-Cerrado medials triggered special reflexes of Proto-Cerrado onsets in Proto-Central Jê, including PCerr ${ }^{*} t w,{ }^{*} k w>$ PCJ ${ }^{*} w$, PCerr ${ }^{*} y w>$ PCJ ${ }^{*} k w$, PCerr ${ }^{*} C y e>$ PCJ ${ }^{*} a \sim{ }^{*} c a$. However, the examples are very limited. They are listed in (17) below.

(17) Interaction of PCerr onsets and medials in PCJ

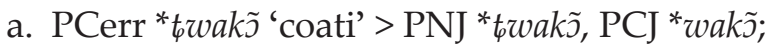

b. PCerr ${ }^{*} y w a$ 'tooth' $>$ PNJ ${ }^{*} d_{i} w a$, PCJ ${ }^{*} k w a$;

c. PCerr ${ }^{*} k V y w a$ 'salt' > PNJ *kad,wa, PCJ ${ }^{*} k a k w a-r z ;$;

d. PCerr *k3ykwa 'sky'> PNJ *kVykwa, PCJ *həywa'19;

e. PCerr * yad $\breve{a}=k w a$ 'mouth' $>$ PNJ * $y a r=k w a, P C J{ }^{*} z a d a=w a$;

f. PCerr *kyey 'thigh' > PNJ *kye, PCJ *3ay // *3a (non-alternating 3);

g. PCerr ${ }^{*}{ }^{n} g y e /{ }^{* n} g y e-d_{\varphi}^{n}$ 'to enter.PL' > PNJ ${ }^{*} g i y a ̆{ }^{* n} g y e-d_{\varphi}{ }^{n}$, PCJ ${ }^{*} z a /{ }^{*} z a-c i$ 'to enter.DU' (non-alternating 3);

h. PCerr *tyetě 'to burn' > PNJ *tyetĕe, PCJ *zata // *3a:da;

i. PCerr ${ }^{*} k y e /{ }^{*} k y e-d^{n}$ 'to drag, to pull' > PNJ ${ }^{*} k y e /{ }^{*} k y e-d^{n}$, PCJ ${ }^{*} c a /{ }^{*} c a-r i$.

Davis (1966: 23) also identifies Xavánte wam // wa 'fat' (PCJ *wam // wa) as a cognate of PNJ ${ }^{*} t w g b^{n} \stackrel{\imath}{\mathrm{id}}$. Since the correspondences of PNJ ${ }^{*} w g$ in Central Jê are otherwise unknown, this comparison is plausible, but still uncertain.

\subsection{Nucleus}

The correspondences between Proto-Northern Jê and Proto-Central Jê nuclei, as well as the proposed Proto-Cerrado reconstructions for these correspondences, are exposed below in Table $6{ }^{20}$.

Table 6. Proto-Cerrado vowels and their reflexes in Proto-Northern Jê and Proto-Central Jê.

\begin{tabular}{|c|c|c|}
\hline PCerr & PNJ & PCJ \\
\hline *a & ${ }^{*} \mathrm{a},{ }^{*} \tilde{\mathrm{a}}^{+}$ & *a \\
\hline$*_{3}$ & $*_{3}$ & \multirow{2}{*}{${ }^{*} \varepsilon_{,}{ }^{*} \partial^{\ddagger}$} \\
\hline *9 & $*_{9}$ & \\
\hline$*_{i}$ & ${ }^{*} \dot{i},{ }^{*} \tilde{i}^{+}$ & ${ }^{*} \partial$ \\
\hline *J & *j & *J \\
\hline *o & $*_{0}$ & \multirow{2}{*}{${ }^{*} \mathrm{u}$} \\
\hline${ }^{*} \mathrm{u}$ & ${ }^{*} \mathrm{u},{ }^{*} \tilde{\mathrm{u}}^{\dagger}$ & \\
\hline${ }^{*} \varepsilon$ & ${ }^{*} \varepsilon$ & ${ }^{*} \mathrm{e}$ \\
\hline${ }^{*} \mathrm{e}$ & ${ }^{*} \mathrm{e}$ & \multirow{2}{*}{$*_{i}$} \\
\hline$*_{i}$ & $*_{i}$ & \\
\hline
\end{tabular}

\begin{tabular}{c|c|c}
\hline PCerr & PNJ & PCJ \\
\hline$*_{\tilde{3}}$ & $*_{\tilde{3}}$ & \multirow{2}{*}{$* \tilde{~}$} \\
\hline$*_{\tilde{1}}$ & $*_{\tilde{1}}$ & \\
\hline$*_{\tilde{j}}$ & $*_{\tilde{\jmath}}$ & $* \tilde{\jmath}$ \\
\hline$*_{\tilde{\varepsilon}}$ & $*_{\tilde{\varepsilon}}$ & $*_{\tilde{\varepsilon}}$ \\
\hline$*_{\tilde{1}}$ & $*_{\tilde{1}}$ & $*_{\tilde{1}}$ \\
\hline
\end{tabular}

$+{ }^{*} \tilde{a},{ }^{*} \tilde{u},{ }^{*} \tilde{z}$ occur before ${ }^{*} m$ in coda. $\ddagger$ PCerr ${ }^{*} k_{3},{ }^{* n} g_{3}>$ PCJ ${ }^{*} h o$.

19 Possibly something other than PCJ ${ }^{*} w$ has to be reconstructed for the reflex of PCerr ${ }^{*} k w$ : in the word for 'sky' a cluster in attested in Xakriabá <akoâ> (Eschwege's notes) and Salinas Xavánte hainuă; however, this is not the case with the word for 'mouth': Xakriabá <d'atohá> (Eschwege), <daïdauá> (S. Hilaire), Salinas Xavánte =sedaua (Martius 1867: 142, Ehrenreich 1895: 151, 153).

${ }^{20}$ Oliveira (2005: 61) cites a talk entitled 'Vowel shift in Central Jê' (Oliveira \& Ribeiro 2005); unfortunately, I have had no access to its abstract. 
As is evident from the table above, Proto-Northern Jê is very conservative in its vocalism. The nasalization of ${ }^{*} a,{ }^{*} u$ and ${ }^{*} i$ before syllable-final ${ }^{*} m$ in Proto-Northern Jê is described in (Nikulin 2016b: 176-177). This is clearly a Proto-Northern Jê innovation: in Central Jê, oral vowels are found, as shown in (18) below.

(18) Proto-Northern Jê innovative nasalization

a. PCerr *tubn 'old, tall (?)' > PNJ *tũmũ, PCJ *dum // *du 'tall', *dum-krata // *dum-kra:da 'elder sibling of the opposite sex';

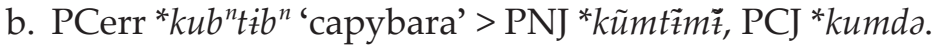

Unlike Proto-Northern Jê, Proto-Central Jê innovated considerably. As a result of a vowel shift, discussed already by Ribeiro and Voort (2010: 554), PCerr ${ }^{*} 9$ and ${ }^{*} 3$ yielded PCJ ${ }^{*} \varepsilon(19 a-i){ }^{21}$, PCerr ${ }^{*} \varepsilon$ was raised to PCJ ${ }^{*} e(19 j-n)$, and PCJ ${ }^{*} e$ and ${ }^{*} o$ merged with ${ }^{*} i$ and ${ }^{*} u$, respectively $(19 \mathrm{o}-\mathrm{y})$ (see subsection 3.1.1 for the effect of this merger on the preceding consonants).

(19) Vowel shift in Proto-Central Jê

a. PCerr ${ }^{* n} b 9 /{ }^{* n} b 9-d_{\varphi}^{n}>\mathrm{PNJ}{ }^{* n} b 9 /{ }^{* n} b 9-d_{\varphi}^{n}$ 'to carry', PCJ ${ }^{*} k w a=p \varepsilon$ 'to carry.DU';

b. PCerr *kurg 'smooth'> PNJ *kurs, PCJ *kure;

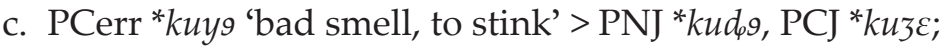

d. PCerr * $y_{9}$ 'bitter' > PNJ * ${ }_{\phi} 9$, PCJ ${ }^{*} z \varepsilon$;

e. PCerr ${ }^{*} t 3 b^{n}$ 'new' $>\mathrm{PNJ}^{*}{ }^{*} b^{n}{ }^{n}$ ' 'raw', $\mathrm{PCJ}{ }^{*} t \varepsilon m / /{ }^{*} t \varepsilon$;

f. PCerr ${ }^{* n} g r 3$ 'dry' $>$ PNJ ${ }^{* n} g r 3$, PCJ ${ }^{*} k r \varepsilon$;

g. PCerr ${ }^{*}=y 3$ (instrumental suffix) $>\mathrm{PNJ}^{*}=d_{4}, \mathrm{PCJ}{ }^{*}=3 \varepsilon$;

h. PCerr ${ }^{*} a^{n} g_{3}$ 'sedge seed' $>$ PNJ ${ }^{*} a^{n} g_{3}, \mathrm{PCJ}{ }^{*} a k \varepsilon$;

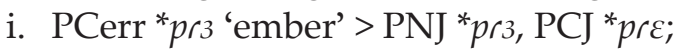

j. PCerr ${ }^{*} t \varepsilon p \breve{\varepsilon}$ 'fish' > PNJ ${ }^{*} t \varepsilon p \breve{\varepsilon}, \mathrm{PCJ}{ }^{*}$ tepe // *te:be;

k. PCerr ${ }^{* n}$ gre 'egg' > PNJ ${ }^{* n} g r \varepsilon$, PCJ ${ }^{*} k r e$;

1. PCerr *tcy 'leg' $>$ PNJ ${ }^{*} t \varepsilon$, PCJ ${ }^{*} t e y / /{ }^{*} t e$;

m. PCerr ${ }^{*} k r \varepsilon$ 'to plant' $>\mathrm{PNJ}{ }^{*} k r \varepsilon, \mathrm{PCJ}{ }^{*} k r e$;

$n$. PCerr ${ }^{*} k r \varepsilon$ 'orifice, hole' $>$ PNJ ${ }^{*} k r \varepsilon, \mathrm{PCJ}{ }^{*}=k r e$;

o. PCerr *terĕ 'fruit of a k. of palm' > PNJ *terĕ, PCJ *tiri // *tiri 'bacuri coconut';

p. PCerr ${ }^{*} t e$ 'tick' $>\mathrm{PNJ}{ }^{*} t e, \mathrm{PCJ}{ }^{*} t i$;

q. PCerr *yate 'nest' > PNJ *yate, PCJ *3aci;

r. PCerr ${ }^{*} k a^{n} d_{\phi} e$ 'star' > PNJ ${ }^{*} k a^{n} d_{\varphi} e, \mathrm{PCJ}{ }^{*} w a: c i$;

s. PCerr *weke 'partridge' > PNJ *beke, PCJ *wiki;

t. PCerr *kupe 'to touch, to move' > PNJ *kupe, PCJ *kupi;

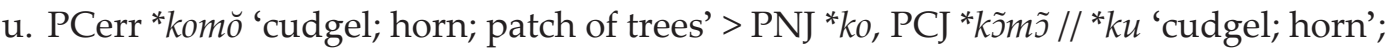

v. PCerr ${ }^{* n} g o y$ 'water' > PNJ ${ }^{* n} g o(t-)$, PCJ *kuy // *ku 'still water';

w. PCerr ${ }^{*} t_{0} y$ 'leaf, a hair' > PNJ ${ }^{*} t_{0}, \mathrm{PCJ}{ }^{*} \mathrm{cuy} / /{ }^{*} \mathrm{cu}$;

x. PCerr *kanbroy 'blood' > PNJ *kan bro, PCJ *wa:pruy // *wa:pru;

y. PCerr *kopo 'fly' > PNJ *kopŏ, PCJ *kupu // *ku:bu, etc.

In addition to the shift, two other developments affected the vocalism of Proto-Central Jê: PCerr * $i$ was lowered to PCJ * $($ PCJ * $i$ occurs in words without any external etymology), and PCerr ${ }^{*} \tilde{z}$ and ${ }^{*} \tilde{z}$ merged in PCJ ${ }^{*} \tilde{z}$. These changes are exemplified in (20) and (21), respectively.

${ }^{21}$ Oliveira and Ribeiro (2005 apud Oliveira 2005: 61) state that ${ }^{*} 3$ and ${ }^{*} 9$ remained distinct in PCJ, yielding ${ }^{*} \varepsilon$ and ${ }^{*} e$, respectively. I was able to identify only one word with PNJ * 9 corresponding to PCJ * $e$ PNJ ${ }^{*} t 9 t \breve{\imath}$ 'hard, strong' PCJ *tete // te:de 'hard, strong'. This should be attributed to an additional sound law: before a coronal stop

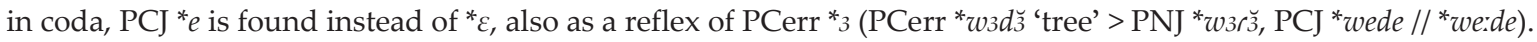


(20) Lowering of PCerr ${ }^{*} i$ in Proto-Central Jê

a. PCerr ${ }^{*} k u b^{n} t \dot{t} b^{n}$ 'capybara' $>$ PNJ ${ }^{*} k \tilde{u} m t \tilde{t} m \tilde{z}$, PCJ ${ }^{*} k u m d$.

b. PCerr * piy 'achiote' > PNJ *pi, PCJ *bay // *ba;

c. PCerr *kutitmü 'fire' > PNJ *kutit, PCJ *kunãmã // *kuza;

d. PCerr ${ }^{*} a m={ }^{n} d_{\phi} \dot{t}$ 'bee sp.' > PNJ ${ }^{*} a m={ }^{n} d_{\phi} i$, PCJ ${ }^{*} a m=3 \partial$;

e. PCerr *nbitü 'sun' > PNJ *nbittŭ, PCJ *bata // *ba:da;

f. PCerr ${ }^{* n} b \dot{i} n \breve{z}$ 'tail, penis' > PNJ *nbi், PCJ *mãnã // *ba, etc.

(21) Merger of PCerr * $\tilde{3}$ and *̃̃ in Proto-Central Jê

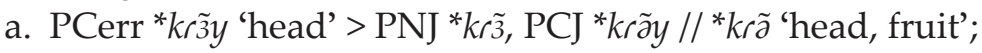

b. PCerr * prĩm 'hungry' > PNJ * $p r \tilde{3} m \tilde{3}$ 'hungry, to want', PCJ * $m r \tilde{a} m / /{ }^{*} m r \tilde{a}$;

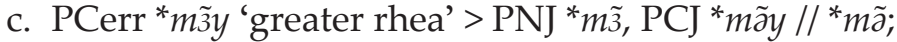

d. PCerr ${ }^{*} n \tilde{3}$ 'mother' > PNJ ${ }^{*} n \tilde{3}, \mathrm{PCJ}^{*} n \tilde{z}$;

e. PCerr ${ }^{*} \eta \tilde{z} /{ }^{*} n \tilde{z}-P r \tilde{z}$ 'to sit.SG' > PNJ ${ }^{*} n \tilde{z} /{ }^{*} n \tilde{z}-r$, PCJ ${ }^{*} n \tilde{\partial}-m r \tilde{a}$ (finite: 2SG ${ }^{*} a y=c \tilde{z}$ );

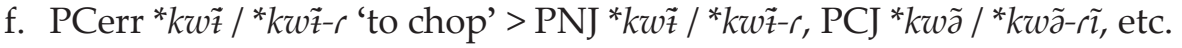

A context-specific development of PCerr ${ }^{*} 3$ after velars has already been treated in subsection 3.1.4.

\subsection{Coda}

Proto-Central Jê codas, as well as Proto-Central Jê alternating rhymes of the classes A, B and D (see 2.3 above), have regular correspondences in Proto-Northern Jê. Proto-Central Jê classes C and $\mathrm{E}$ are of unknown origin. The most secure correspondences are listed in Table 7 below.

Table 7. Proto-Cerrado codas and their reflexes in Proto-Northern Jê and Proto-Central Jê.

\begin{tabular}{c|c|c}
\hline PCerr & PNJ & PCJ \\
\hline$*-p \breve{V}$ & ${ }^{*}-p \breve{V}$ & $*-p V(\mathrm{D})$ \\
\hline$*-t \breve{V}$ & $*-t \breve{V}$ & $*-t V(\mathrm{D})$ \\
\hline$*-k \breve{V}$ & $*-k \breve{V}$ & $*-k V(\mathrm{~A})$ \\
\hline$*-r \breve{V}$ & $*-r \breve{V}$ & $*-r V(\mathrm{D})$ \\
\hline$*-r$ & $*-r$ & $*-r \breve{l}$ \\
\hline
\end{tabular}

\begin{tabular}{c|c|c}
\hline PCerr & PNJ & PCJ \\
\hline${ }^{*}-m \breve{V}$ & ${ }^{*} \varnothing \varnothing$ & ${ }^{*}-\mathrm{m} \tilde{V}(\mathrm{~B})$ \\
\hline${ }^{*}-n \breve{V}$ & ${ }^{*} \varnothing$ & ${ }^{*}-\mathrm{n} \tilde{V}(\mathrm{~B})$ \\
\hline${ }^{*}-\eta \breve{V}$ & ${ }^{*}-\varnothing$ & ${ }^{*}-\mathrm{kV}(\mathrm{A})$ \\
\hline$*-y$ & ${ }^{*}-\varnothing$ & ${ }^{*}-\mathrm{y}$ \\
\hline$*-b^{n} /{ }^{*}-m$ & $*-b^{n} \breve{\imath} /{ }^{*}-m \breve{V}$ & $*-\mathrm{m}$ \\
\hline
\end{tabular}

Note that some codas that are reconstructible to Proto-Northern Jê do not occur in words with secure Cerrado, Jê or Macro-Jê etymologies. These include PNJ *-w $\breve{V}$ and ${ }^{*}-y \breve{\imath} 22$. I suggest that such words entered Proto-Cerrado as loans from an unknown North Amazonian language: words like PNJ *kukoyı̆ 'monkey' and PNJ *ndiwä 'new'23 are suspiciously similar to Hup kukúy, Yanomama ku(u)ku-moxi 'night monkey' and Hup 'd’ow-áy 'new', respectively (Nikulin \& Carvalho 2017: 38).

\subsubsection{Voiceless codas in Proto-Cerrado}

As is evident from the table above, Proto-Northern Jê voiceless stops in coda position correspond to PCJ voiceless stops in coda utterance-medially. PCJ ${ }^{*} p$ and ${ }^{*} t$, on one side, and PCJ ${ }^{*}$,

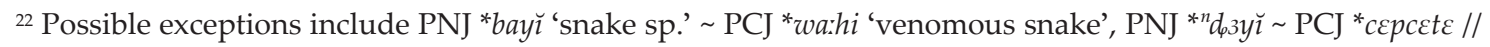
cepce:de 'woodpecker'. Both comparisons are dubious.

${ }^{23}$ Erroneously glossed as 'field' in (Nikulin 2016b: 180). 
on the other, behave differently. PCJ stems in ${ }^{*}-p V$ and ${ }^{*}-t V$ belong to class $\mathrm{D}$, as shown in (22) below, whereas PCJ stems in * $k V$ belong to class A, as exemplified in (23).

(22) PCerr stems in ${ }^{*}-p \breve{V},{ }^{*}-t \breve{V}$

a. PCerr ${ }^{*} k o p o \breve{~ ' f l y ' ~>~ P N J ~ * k o p o ̆, ~ P C J ~ * k u p u ~ / / ~ * k u: b u ; ~}$

b. PCerr ${ }^{*} t \varepsilon p \breve{\varepsilon}$ 'fish' > PNJ ${ }^{*} t \varepsilon p \breve{\varepsilon}, \mathrm{PCJ}{ }^{*} t \varepsilon p \varepsilon / /{ }^{*} t \varepsilon: b \varepsilon$;

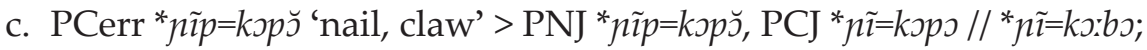

d. PCerr *nbitť 'sun' > PNJ *nbitü, PCJ *bata // *ba:da;

e. PCerr *"butŭ 'neck' > PNJ *nbutŭ, PCJ *butu // ${ }^{*} b u: d u$;

f. PCerr ${ }^{*} n \tilde{\nu}=k o t o ̆ ~ ' c h e s t '>$ PNJ ${ }^{*} n \tilde{\nu}=k o t \breve{o}$, PCJ ${ }^{*} n \tilde{\nu}=k u t u / /{ }^{*} n \tilde{\nu}=k u: d u$;

g. PCerr *tyetĕ 'to burn'> PNJ *tyetĕ, PCJ *3ata // *3a:da;

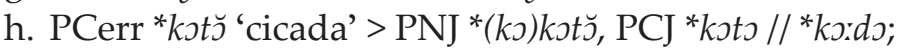

i. PCerr *kukritü 'tapir' > PNJ *kukritü, PCJ *kuta // *kuha:da;

j. PCerr ${ }^{*} k r i t \grave{\imath}$ 'grasshopper' > PNJ ${ }^{*} k r i t \grave{i}, \mathrm{PCJ}{ }^{*} k r i t i / /{ }^{*} k r i$ di;

k. PCerr *krată 'base' > PNJ *kratı̆ 'base, stem, lower part of the body', PCJ *krata // *kra:da 'base, beginning; near; grandparent';

1. PCerr *rîtĩ 'to look' > PNJ *ritur, PCJ *rĩtĩ // *rĩnnĩ, etc.

In one instance, the final consonant has apparently been irregularly nasalized in Proto-

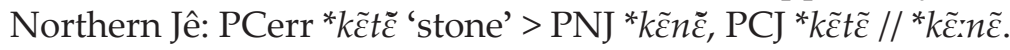

(23) PCerr stems in *- $k \breve{V}$

a. PCerr *kokŏ 'wind' > PNJ *kokŏ, PCJ ${ }^{*} r{ }^{*}=w a=k u k u / /{ }^{*} c^{\prime}=w a=k u$;

b. PCerr *tikì 'belly' > PNJ ${ }^{*} t i k \grave{\imath}, \mathrm{PCJ}{ }^{*} d i k i / /{ }^{*} d i$;

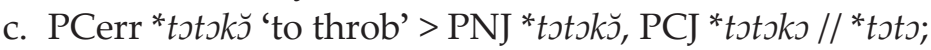

d. PCerr *kakă 'to cough'> PNJ *kakŭ, PCJ *kaka;

e. PCerr ${ }^{* n}$ grikẗ 'angry, upset' > PNJ ${ }^{* n}$ griktu, PCJ *haka;

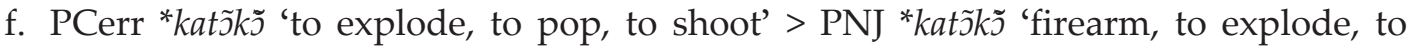
pop', PCJ *wañ̃ $k \tilde{\jmath}$ 'to explode, to attack', etc.

Utterance-final allomorphs of Central Jê counterparts of the cognate sets (23d-f) have not been attested, but these stems are expected to belong to class A.

\subsubsection{Rhotic codas in Proto-Cerrado}

I reconstruct two types of Proto-Cerrado stems with a rhotic coda. Just like in Proto-Northern Jê (Nikulin 2016b: 182), rhotic coda followed by an echo vowel would have been characteristic of nouns. In Central Jê, it patterns with PCerr ${ }^{*}-p \breve{V}$ and ${ }^{*}-t \breve{V}$ (class D stems). On the other hand, non-finite forms of verbs would have featured a rhotic with a suppressed echo vowel. In this case, a final ${ }^{*} i$ is inserted in Central Jê $\left({ }^{*}-\tilde{\imath}\right.$ if the preceding syllable carries nasality). This is shown in (24) below.

(24) Distinction between PCerr ${ }^{*}-r \breve{V}$ and ${ }^{*}-r$

a. PCerr *pară 'foot' > PNJ *pař̆, PCJ *para // * parra;

b. PCerr *purŭ 'field' > PNJ *purŭ, PCJ *buru // *burcu;

c. PCerr *terĕ 'fruit of a k. of palm'> PNJ *terĕ, PCJ *tiri // *tirri 'bacuri coconut';

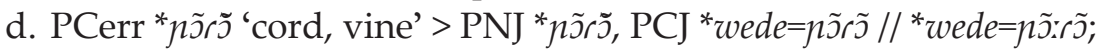

e. PCerr ${ }^{*} w \tilde{\imath} /{ }^{*} w \tilde{\imath}-r$ 'to kill' $>$ PNJ ${ }^{*} b \tilde{\imath} /{ }^{*} b \tilde{\imath}-r, \mathrm{PCJ}{ }^{*} w \tilde{\imath} /{ }^{*} w \tilde{\imath}-r \tilde{\imath}$;

f. PCerr ${ }^{*} p a /{ }^{*} p a-r$ 'to finish' $>$ PNJ * $p a /{ }^{*} p a-r$, PCJ * $p a /{ }^{*} p a-r i$ 'to finish, to erase';

g. PCerr ${ }^{*} t u /{ }^{*} t u-r$ 'to carry' $>\mathrm{PNJ}{ }^{*} t u /{ }^{*} t u-r, \mathrm{PCJ}{ }^{*} d u /{ }^{*} d u-r i$;

h. PCerr ${ }^{* n} d_{a} a{ }^{* n} d_{a} a-r$ 'to bite' $>$ PNJ ${ }^{* n} d_{a} a /{ }^{* n} d_{\varphi} a-r$, PCJ ${ }^{*} c a /{ }^{*} c a-r i$, etc. 
However, the allomorph *-ri cannot be attached to Central Jê reflexes of PCerr roots ending in certain vowels, like ${ }^{*} 3$ and ${ }^{*} \tilde{\varepsilon}$. Allomorphs with echo vowels may be found in such cases, cf. PCJ ${ }^{*} h a /{ }^{*} h \partial-r a$ 'to shout' $\left(<\right.$ PCerr $\left.{ }^{*} k_{3} /{ }^{*} k 3-r\right)$.

\subsubsection{Nasal codas in Proto-Cerrado}

Central Jê stems that belong to class B correspond to vowel-final stems in Proto-Northern Jê. I reconstruct nasal codas followed by an echo vowel. The correspondence is exemplified in (25) below.

(25) Proto-Cerrado etyma yielding Central Jê class B stems

a. PCerr *pĩmü 'firewood' > PNJ *pi 'wood', PCJ *mĩmi // *mĩ;

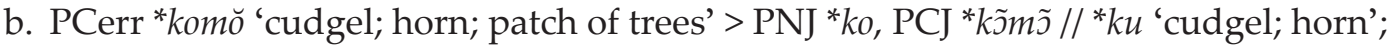

c. PCerr *kutimü 'fire' > PNJ *kutí, PCJ *kunãmã // *kuza;

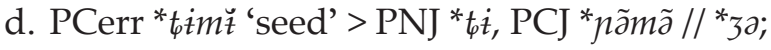

e. PCerr $\left.{ }^{* n} d\right\lrcorner m \breve{\jmath}$ 'eye' > PNJ $\left.{ }^{* n} d\right\lrcorner(p-)$, PCJ *tõm $/{ }^{*} t$;

f. PCerr *nbinü 'tail, penis' > PNJ *nbi, PCJ *mãnã // *ba;

g. PCerr *tumŭ 'belly'> PNJ *tu, PCJ *ñ̃m $/ /{ }^{*} d u$, etc.

The Proto-Northern Jê consonant-final allomorph ${ }^{* n} d s p-(25 \mathrm{e})$ is preserved only in Apinayé, where it occurs before any elements in postposition (Ham 1961: 27; Oliveira 2005: 375). The final consonant $-p$ must be understood as a relic of the Proto-Cerrado coda.

For Central Jê class A stems ending in *-kV that correspond to zero in PNJ, I suggest reconstructing PCerr ${ }^{*}-\eta \breve{V}$. The denasalization of ${ }^{*} \eta$ in PCJ is expected: no such phoneme can be reconstructed for PCJ, even in the onset position. The clearest examples are provided in (26).

(26) Proto-Cerrado* $-\eta \breve{V}$

a. PCerr * $p э \eta \breve{\jmath}$ 'arrow, bamboo' > PNJ *po- te 'bamboo', PCJ *poks // * $p$ 'big arrow';

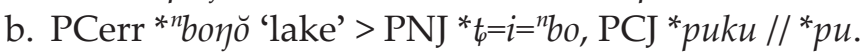

At first sight, the reconstruction of a velar segment for this correspondence conflicts with external data: probable Maxakalí cognates of these words are pohox / puC/ 'arrow' and puxhep /piC-heP/ 'lake', with palatal codas. However, PCerr * $\eta$ may correspond to Maxakalí palatals

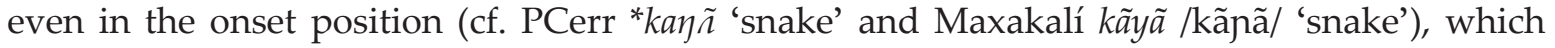
renders the reconstructive hypothesis in question plausible.

\subsubsection{Palatal coda in Proto-Cerrado}

Proto-Central Jê stems whose underlying representations end in */-y/ correspond to vowelfinal stems in Proto-Northern Jê. I reconstruct PCerr ${ }^{*}-y$ for this correspondence. Some examples are provided in (27).

(27) Proto-Cerrado stems in *-y

a. PCerr ${ }^{*} t \tilde{\jmath} y$ 'brother' $>$ PNJ ${ }^{*} t \tilde{\jmath}, \mathrm{PCJ}^{*} n \tilde{\mathcal{\partial}} y / /{ }^{*} n \tilde{\mathcal{\nu}}$ 'younger sibling of the same sex';

b. PCerr * $m \tilde{z} y$ 'greater rhea' > PNJ * $m \tilde{3}, \mathrm{PCJ}{ }^{*} m \tilde{a} y / /{ }^{*} m \tilde{a}$;

c. PCerr ${ }^{* n}$ goy 'water' > PNJ ${ }^{* n} g o(t-)$, PCJ ${ }^{*} k u y / /{ }^{*} k u$ 'still water';

d. PCerr ${ }^{*} k r \tilde{3} y$ 'head' > PNJ ${ }^{*} k r \tilde{3}$, PCJ ${ }^{*} k r a \tilde{y} / /{ }^{*} k r \tilde{a}$ 'head, fruit';

e. PCerr * piy 'achiote' > PNJ *pi, PCJ *bay // *ba;

f. PCerr ${ }^{*} k a^{n} b r o y$ 'blood' > PNJ *kan bro, PCJ *wa:pruy // *wa:pru;

g. PCerr ${ }^{*}$ toy 'leaf, a hair' $>\mathrm{PNJ}{ }^{*}{ }^{\circ} \mathrm{o}, \mathrm{PCJ}{ }^{*} \mathrm{cuy} / /{ }^{*} \mathrm{cu}$; 
h. PCerr *k3y 'skin, bark, breast' > PNJ *k3, PCJ *həy;

i. PCerr *kyey 'thigh' > PNJ *kye, PCJ *3ay // * $3 a$;

j. PCerr *tcy 'leg' > PNJ *te, PCJ *tey // *te;

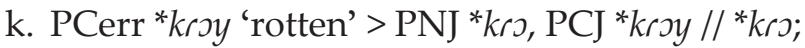

1. PCerr * $m \tilde{\varepsilon} y$ 'to throw.SG' $>$ PNJ ${ }^{*} m \tilde{\varepsilon} /{ }^{*} m \tilde{\varepsilon}-n, \mathrm{PCJ}{ }^{*} m \tilde{\varepsilon} y / /{ }^{*} m \tilde{\varepsilon}$, etc.

In (27c), one Northern Jê language (Apinayé) retains two allomorphs: ${ }^{n} g o$ and ${ }^{n} g o y c ̌-(b e-$ fore any elements in postposition, see Ham 1961: 27); I reconstruct PNJ ${ }^{* n} g_{o}\left(t_{-}\right)$. The correspondence under examination also seems to be valid word-medially: PCerr *ñ̃yto 'tongue' > PNJ * $n \tilde{\partial} t$, PCJ * $n \tilde{\partial} y$ to.

\subsubsection{Labial coda in Proto-Cerrado not followed by an echo vowel}

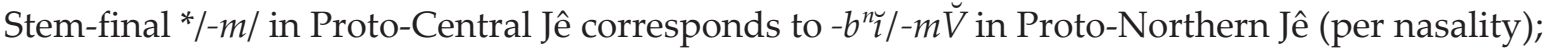
I reconstruct PCerr ${ }^{*}-\left.b^{n}\right|^{*}-m$ for this correspondence. It is instantiated in the stems listed in (28).

(28) Proto-Cerrado stems in ${ }^{*}-b^{n} /{ }^{*}-m$

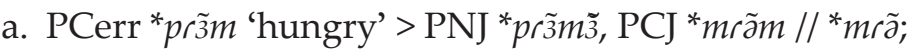

b. PCerr ${ }^{*} t \tilde{\varepsilon} /{ }^{*} t \tilde{\varepsilon}-m$ 'to go.SG' > PNJ ${ }^{*} t \tilde{\varepsilon} /{ }^{*} t \tilde{\varepsilon}-m, \mathrm{PCJ}{ }^{*} n \tilde{\varepsilon}-m / /{ }^{*} n \tilde{\varepsilon}$ 'to go.DU';

c. PCerr *tub 'old, tall (?)' > PNJ *tũmũ, PCJ *dub // du 'tall', *dub-krata // *dub-kra:da 'elder sibling';

d. PCerr * $y o b^{n}$ 'to grind' > PNJ * $d_{\varphi} o b^{n}$ 'flour, powder', PCJ * $3 u m / /{ }^{*} z u$;

e. PCerr ${ }^{*} t 3 b^{n}$ 'new' $>$ PNJ ${ }^{*} t 3 b^{n} \iota$ ' raw', PCJ ${ }^{*} t \varepsilon m / /{ }^{*} t \varepsilon$, etc.

The utterance-internal allomorph of PCJ ${ }^{*} k u m d a ~\left(<\right.$ PCerr ${ }^{*} k u b^{n} t i b^{n}$ 'capybara', cf. PNJ $\left.{ }^{*} k \tilde{u} m t \tilde{t} m \tilde{z}\right)$ is unattested, but the predicted form is ${ }^{*} k u m d a m$.

\subsubsection{Complex codas in Proto-Cerrado}

In a number of stems, $\mathrm{PNJ}{ }^{*}-r \breve{V}$ or ${ }^{*}-r$ correspond to $\mathrm{PCJ}{ }^{*}-b r V{ }^{*}-m r V$. I tentatively reconstruct PCerr ${ }^{*}-\operatorname{Pr} \breve{V}$ for these cases. Some examples are provided in (29) below.

(29) $\quad \mathrm{PCerr}^{*}-\operatorname{PrV}$ and its reflexes

a. PCerr ${ }^{*} y_{3} /{ }^{*} y_{3}-P r \breve{z}$ 'to enter.SG' > PNJ ${ }^{*} d_{\phi} 3 /{ }^{*} d_{3} 3-r, P C J{ }^{*} z \varepsilon /{ }^{*} z \varepsilon-b r \varepsilon$;

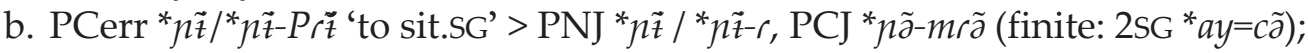

c. PCerr ${ }^{*} n \tilde{\jmath} /{ }^{*} n \tilde{\jmath}-P r \tilde{\jmath}$ 'to lie.SG' > PNJ ${ }^{*} n \tilde{\jmath} /{ }^{*} n \tilde{\jmath}-r, P C J{ }^{*} n \tilde{\jmath} /{ }^{*} n \tilde{\jmath}-m r \tilde{\jmath} ;$

d. PCerr *yuPrŭ 'pus' > PNJ *du $\sim{ }^{*} d_{\varphi} u r \breve{u}$, PCJ *zubruy;

e. PCerr ${ }^{*} k a=t \jmath /{ }^{*} k a=t \jmath-P r \breve{\jmath}$ 'to leave, to go out' $>$ PNJ ${ }^{*} k a=t \jmath /{ }^{*} k a=t \jmath-r$ 'to leave, to go out, to be born', PCJ *wa=to/*wa=to-bro, etc.

It is possible that PCJ *tobro 'to get down (Xavánte), to cross a body of water (Xerénte)' and PCJ ${ }^{*} c e b r e$ 'to roast (Xavánte), to become soft, cooked (Xerénte)' are related to PNJ ${ }^{*}$ to/ ${ }^{*}$ to'to fly, to dance' and ${ }^{*} g a /{ }^{*} d_{33}-r$ 'to roast', but this is far from certain. I have no explanation for Central Jê non-finite forms in ${ }^{*}-m r \tilde{\imath}$, like PCJ ${ }^{*} c \tilde{\partial} /{ }^{*} c \tilde{\partial}-m r \tilde{\imath}$ 'to find', ${ }^{*} c \tilde{\jmath} /{ }^{*} c \tilde{\jmath}-m r \tilde{\imath}$ 'to give', ${ }^{*} c a c \tilde{\jmath} /$

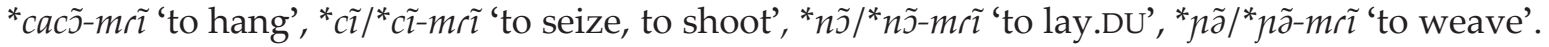
These verbs must be accounted for by future research.

Yet another possible instance of a complex coda in Proto-Cerrado is suggested by a handful of verbs that have two different forms in Proto-Central Jê: a form in ${ }^{*}-k \breve{V}$ and a form in ${ }^{*}-\varsigma \breve{V}$ (cf. PCJ ${ }^{*} t \jmath=p \jmath-k \jmath /{ }^{*} t \jmath=p \jmath-r \jmath$ 'to open one's eyes, to wake up'; ${ }^{*} p u-k u /{ }^{*} p u-r u$ 'to pierce', ${ }^{*} d a k a / /$ *da/*dara //*darra 'to die', 'waptz̃-kã/waptz̃-rã 'to fall, to be born.SG/DU', etc.). The syntactic distri- 
bution of these forms is not fully explored. I abstain from reconstructing Proto-Cerrado forms in ${ }^{*}-k r \breve{V}$ for the verbs that feature the phenomenon in question, but such a solution remains a possibility.

\subsubsection{Other possible codas in Proto-Cerrado}

PCerr ${ }^{*} d$ also seems to have occurred in coda position, but only two examples have been identified so far; these are listed in (30).

(30) Evidence for reconstructing PCerr * $-d V$

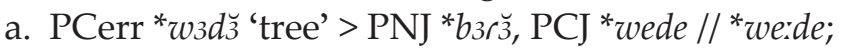

b. PCerr *yad-kwa 'mouth' > PNJ *yar-kwa, PCJ *zada-wa.

I was unable to identify regular PCJ correspondences of the PNJ codas ${ }^{*}-t_{\varphi},{ }^{*}-d^{n}(\breve{l}),{ }^{*}-d_{\varphi}^{n}(\breve{l})$, ${ }^{*} n \breve{V}$ due to the scarcity of available examples. I provisionally project these PNJ codas to ProtoCerrado, but a better solution is likely to be possible. Some examples are provided in (31).

(31) Tentatively reconstructed Proto-Cerrado codas

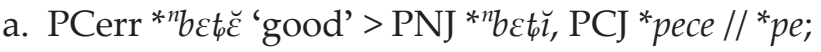

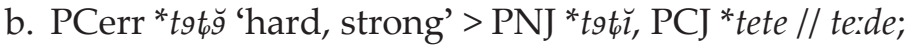

c. PCerr ${ }^{*} k y e /{ }^{*} k y e-d^{n}>\mathrm{PNJ}{ }^{*} k y e /{ }^{*} k y e-d^{n}$ 'to drag, to pull', PCJ ${ }^{*} \mathrm{ca} /{ }^{*} \mathrm{ca}-\mathrm{ri}$;

d. PCerr ${ }^{* n} g y e /{ }^{* n} g y e-d_{\varphi}^{n}$ 'to enter.PL' > PNJ ${ }^{* n}$ giyă $/{ }^{* n} g y e-d_{\varphi}^{n}$, PCJ ${ }^{*} 3 a /{ }^{*} 3 a-c i$ 'to enter.DU';

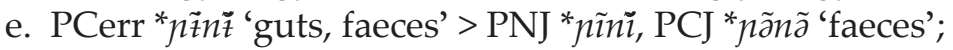

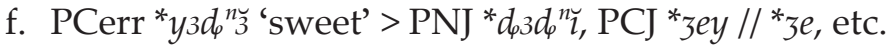

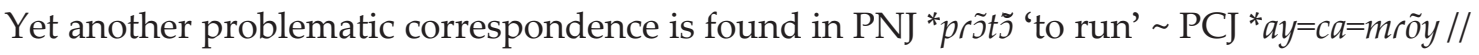
* $a y=c a=m r \tilde{o}$ 'to run.DU', if only this comparison is valid.

\subsubsection{Notes on echo vowels}

The phenomenon of echo vowels, reconstructed by me for Proto-Northern Jê (Nikulin 2016b: 169, 182), undoubtedly existed in Proto-Cerrado. However, certain particularities of its realization reconstructible for Proto-Northern Jê might have not existed in Proto-Cerrado. For instance, the height dissimilation after the nucleus * $a$ seems to be a PNJ innovation, since in PCJ a copy of the nucleus appears in the echo vowel position (cf. PCerr *pară 'foot' > PNJ *parı̆, PCJ

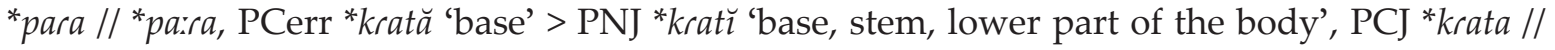
*kra:da 'base, beginning; near; grandparent'; PCerr *kakă 'to cough' > PNJ *kakŭ, PCJ *kaka, etc.). The presence of the echo-vowel ${ }^{*}-\breve{l}$ after palatal and post-nasalized codas in Proto-Northern Jê also appears to be innovative. That way, in my reconstruction Proto-Cerrado echo vowels were always identical to the nucleus.

Note that the suppression of the echo vowels in the non-finite forms of the verbs can be securely reconstructed to Proto-Cerrado. In Proto-Central Jê, PCerr *-r yielded *-ri/*-rĩ (according to the nasality of the nucleus). In Proto-Northern Jê, the contrast between PCerr ${ }^{*}-r \breve{V}$ and * -r seems to have been retained, though it has been deteriorated in most modern Northern Jê languages (see Nikulin 2016b: 182 for traces of this contrast).

\subsubsection{Unexpected nasalization in Proto-Central Jê}

A number of Central Jê stems exhibit an unexpected nasalization of the stem vowel. They are listed in (32) below. 
(32) Unexpected nasalization in Proto-Central Jê

a. PCerr ${ }^{*} r \varepsilon$ 'to leave' $>\mathrm{PNJ}{ }^{*} r \varepsilon, \mathrm{PCJ}{ }^{*} r \tilde{\varepsilon} /{ }^{*} r \tilde{\varepsilon}-m \tilde{\varepsilon}$ 'to leave.SG';

b. PCerr ${ }^{* n}$ day 'rain' > PNJ ${ }^{* n} d a$, PCJ *tãy //*tã;

c. PCerr ${ }^{*} t u /{ }^{*} t u-r$ 'to urinate' $>\mathrm{PNJ}{ }^{*} t u /{ }^{*} t u-r, \mathrm{PCJ}{ }^{*} t \tilde{\nu} /{ }^{*} t \tilde{\jmath}-r \tilde{i}$;

d. PCerr *pa/*pa-r 'to kill'> PNJ *pa/*pa-r, PCJ * $p \tilde{z} /{ }^{*} p \tilde{z}-r \tilde{\imath}$ 'to kill.DU';

e. PCerr ${ }^{* n} g_{r \varepsilon} /{ }^{* n} g r \varepsilon-r$ 'to sing, to dance' > PNJ ${ }^{* n} g r \varepsilon /{ }^{* n} g r \varepsilon-r$, PCJ ${ }^{*} a y=k r \tilde{\varepsilon} /{ }^{*} a y=k r \tilde{\varepsilon}-n \tilde{\varepsilon}$ 'to dance.SG'.

Note that this nasalization cannot have preceded the occlusive merger (see subsection 3.1.1); otherwise, nasal occlusives would have been expected in 32b-d. Moreover, it cannot be easily explained away as a sporadic process postdating the occlusive merger: in this case PCJ ${ }^{* *} n \tilde{\jmath} /^{* *} n \tilde{\jmath}-r \tilde{\imath}$ 'to urinate' $\left(<{ }^{* *} d u /^{* *} d u-r i\right)$ would be the expected form. Presently I have no explanation for this correspondence.

\section{Cerrado etymologies}

This section contains the cognate sets upon which the observations made in this paper are based.

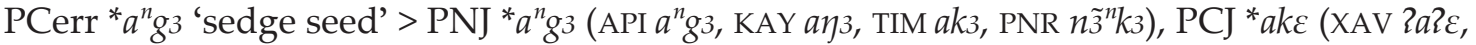
XER $a k \varepsilon)$;

PCerr *n $b a$ 'liver' > PNJ *n $b a$ (API ${ }^{n} b a$, KAY $m a$, SUY, TAP ${ }^{n} b a$, TIM $p a /=m p a$, PNR $\left.\tilde{\imath}^{n} p a\right)$, PCJ * $p a$ (XAV, XER pa);

PCerr * $\left.b a\right|^{* n} b a-r$ 'to hear, to listen' > PNJ *nbal*nba-r 'to hear, to know, to listen' (API ${ }^{n} b a /{ }^{n} b a-r$, KAY $m a / m a-r \breve{\imath}$, TIM $p a / p a-r /=m p a /=m p a-r$, SUY ${ }^{n} b a /{ }^{n} b a-y$, TAP ${ }^{n} b a / b a-y$, PNR $\left.i^{n} p a-r \breve{l}\right)$, PCJ ${ }^{*} w a=p a /{ }^{*} w a=p a-r i$ 'to hear, to listen, to obey' (XAV wa=pa/wa=pa-ri, XER $w a=p a / w a=p a-r i$ $w a=p a-r)$;

PCerr ${ }^{* n} b a$ 'afraid' $>$ PNJ ${ }^{*}=n b a$ (API ${ }^{n} b a$, KAY $=m a$, SUY $=^{n} b a$, TAP ${ }^{n} b a$, TIM $p a$, PNR $\left.y \tilde{u}=p a \eta\right)$, PCJ *pa-hi (XAV pa-hi, XER pa-hi), PCJ *pi=pa (XAV pi=pa, XER pi=pa);

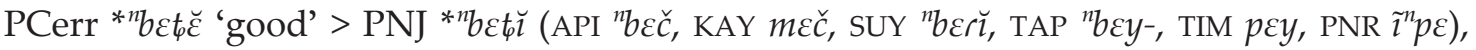
PCJ *pece // *pe (XAV pece // pe 'well; to recover, to get better', XER pese // pe 'good, beautiful');

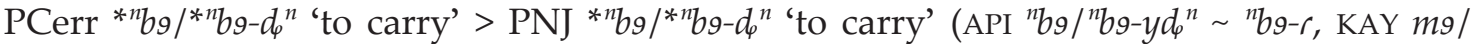
$m 9-y d_{\varphi}^{n}$ 'to grab', TIM $p 9 / p 9-d^{n}$, SUY ${ }^{n} b 9 /{ }^{n} b 9-d^{n} \breve{l}$ ' to grab', (?) PNR $\left.\tilde{\imath}^{n} p \dot{i}-r \breve{l}\right)$, PCJ * $k w a=p \varepsilon$ 'to carry.DU' $(\mathrm{XAV}\{w a=p \varepsilon$, XER $k w a=p \varepsilon)$;

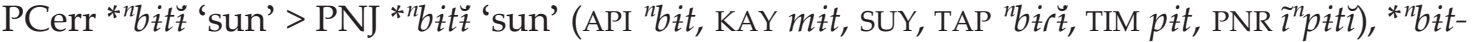
rwg 'moon' (API 'bit-vrs, KAY miti-rwg, SUY 'bit-lws, TIM pit-wrs), PCJ *bata // *ba:da 'sun, day' (XAV bata // baida 'sun, day, hour', XER bda 'sun, day, god');

PCerr *nbin̆ 'tail, penis; man' > PNJ *n $b \dot{t}$ (API $y a={ }^{n} b \dot{i}$ 'tail', 'bi 'man', KAY ya=mi 'tail', $m \dot{t}$ 'man', SUY "bi 'tail, penis', $m \tilde{\varepsilon}==^{n} b \dot{i}-y e$ 'man', TAP " $b \dot{i}$, TIM $y a=p \dot{i}$ 'tail', $m p \dot{i}$ 'man', PNR $y \tilde{3}==^{n} p \dot{i}$ 'tail', $i^{n} p \dot{i}$ 'man'), PCJ *mãnã // *ba 'tail, penis' (XAV mãnã // bo, XER mnã // bə 'tail'), *ay=ba 'man' (XAV zay $=b \partial$, XER $a m=b \partial)$;

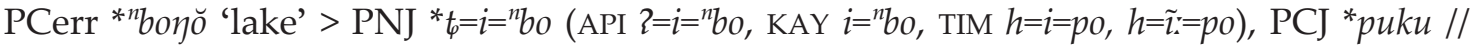
*pu (XAV pu?u // pu 'lake with a spring', XER pku);

PCerr *nbro 'ashes' > PNJ *nbro (API 'bro, KAY mro, TIM pro), PCJ *wede=pro 'coal' (XAV wede=pro 'coal; coffee', XER wde=pro 'coal; coffee; sawdust'), *k $k=3 a y=p r o$ 'foam; beer' (XAV 2z=3ay=pro, XER $k \partial=z a \tilde{\imath}=p r o \sim k \partial=z a m=p r o$ ), *3aday=pro 'saliva' (XAV zaday=pro, XER zdaĩ=pro 'saliva'), (?) *pro 'to burn' (XER pro);

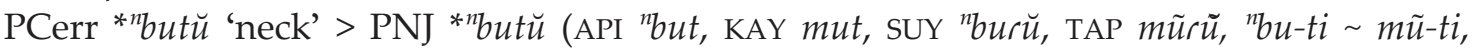
TIM put, PNR in put '̌ 'nape'), PCJ *butu // *bu:du (XAV butu // bu:du, XER bdu); 
PCerr ${ }^{*}={ }^{n} b u y$ 'to see' $>$ PNJ ${ }^{*}=\left.p u\right|^{*}=p u-d_{\varphi}^{n}$ (API $=^{n} b u /={ }^{n} b u-y d_{\varphi}{ }^{n}$, KAY $m \tilde{u} / m \tilde{u}-y n$, SUY $={ }^{n} b u$, TAP $\left.m \tilde{u}, \operatorname{TIM}=p u /=p u-d^{n}, \operatorname{PNR} p u \eta \sim p \tilde{u} /={ }^{n} p u \eta \sim={ }^{n} p \tilde{u}\right), \operatorname{PCJ}{ }^{*} z a=b u y / /{ }^{*} z a=b u\left(\operatorname{XAV} z a=b u y / /{ }^{*} z a=b u\right.$, XER $z a=b u$ ), * $p i=b u y / /{ }^{*} p i=b u$ (XAV $p i=b u y / / p i=b u$ 'to know how to, to control, to care, to observe, to tame'), XER $p i=b u$ 'to observe, to visit');

PCerr ${ }^{* n} d a y$ 'rain' > PNJ ${ }^{* n} d a$ (API ${ }^{n} d a$, KAY na, SUY, TAP ${ }^{n} d a$, TIM $t a$, PNR $\left.i^{n} t a\right)$, PCJ *tãy $/ /{ }^{*} t \tilde{a}$ (XAV, XER tãy // tã);

PCerr ${ }^{* n} d \jmath m \breve{s}$ 'eye' > PNJ *ndo(p-) (API ${ }^{n} d \jmath(p-)$, KAY $n o$, SUY, TAP ${ }^{n} d o$, TIM to/=nto, PNR $\left.\tilde{\imath}^{n} t \jmath\right)$,

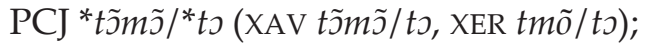

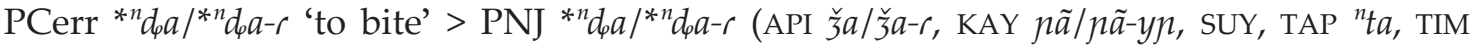
$c a / c a-r /=n c a /=n c a-r$, PNR $\left.i^{n} s a / i^{n} s a-r \breve{l}\right), P C J{ }^{*} c a /{ }^{*} c a-r i(X A V c a / c a-r i$, XER $s a / s a-r i \sim\{a-r)$;

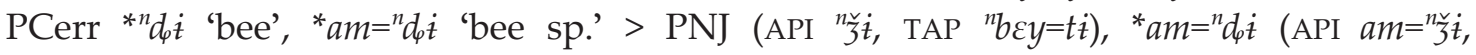
KAY $a m=y \dot{i}, \mathrm{TIM} a m=c \dot{z}), \mathrm{PCJ}{ }^{*} a m=3 \partial$ (XAV $a b=3 \partial$ 'bee sp. (Tetragona clavipes)', XER $a m=z \partial$ 'Brazilian wasp (Protonectarina sylveirae)');

PCerr ${ }^{* n_{3}}{ }_{3}$ 'men's house' > PNJ ${ }^{* n} g_{3}$ 'men's house, courtyard' (API " $g_{3}(p-$ ), KAY $\eta 3$, SUY, TAP "g3, TIM k3), PCJ *ha 'young men's house' (XAV ha);

PCerr ${ }^{*}{ }^{g} g o$ 'louse' > PNJ ${ }^{*} g o$ (API ${ }^{n} g o$, TAP ${ }^{n} g o$, TIM $k o /=\eta k o$, PNR $\left.k y \tilde{s}=k o\right)$, PCJ ${ }^{*} k u($ XAV $\imath u)$;

PCerr ${ }^{* n} g o y$ 'water' > PNJ ${ }^{* n} g o\left(t_{-}\right)$(API ${ }^{n} g o\left(y \check{c}^{-}\right)$, KAY $\eta o$, SUY, TAP ${ }^{n} g o$, TIM $k o$, PNR $i^{n} k o$ ), PCJ *kuy // *ku 'still water' (XAV $2 u y / / \imath u$, XER kuy-);

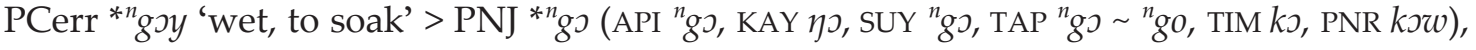
PCJ *koy // *ko (XER koy // ko);

PCerr ${ }^{* n} g r \varepsilon$ 'egg, testicle' > PNJ ${ }^{* n} g r \varepsilon$ (API ${ }^{n} g r \varepsilon$, KAY $\eta r \varepsilon$, SUY ${ }^{n} g \mathcal{d} \mathcal{d}$, TAP ${ }^{n} g_{b \varepsilon}$, TIM $k r \varepsilon /=\eta k r \varepsilon$, PNR $\left.i^{n} k r \varepsilon\right)$, PCJ *kre 'egg' (XAV 2re, XER kre);

PCerr ${ }^{* n} g r \varepsilon /{ }^{* n} g r \mathcal{\delta}-r$ 'to sing, to dance' > PNJ ${ }^{* n} g r \varepsilon /{ }^{* n} g r \mathcal{E}-r$ (API ${ }^{n} g r \varepsilon /{ }^{n} g r \varepsilon-r$, KAY $\eta r \varepsilon / \eta r \varepsilon-r \breve{\varepsilon}$ 'to sing', SUY ${ }^{n} g \varepsilon-l \breve{\varepsilon}$, TAP ${ }^{n} g G \varepsilon /{ }^{n} g \varepsilon-r \breve{\varepsilon}$, TIM $\left.k r \varepsilon\right)$, PCJ ${ }^{*} a y=k r \tilde{\varepsilon} /{ }^{*} a y=k r \tilde{\varepsilon}-n \tilde{\varepsilon}$ 'to dance.SG' (XAV $a y=2 r \tilde{\varepsilon} / a y=2 r \tilde{\varepsilon}-n \tilde{\varepsilon})$;

PCerr ${ }^{*} g_{g r 3}$ 'dry' > PNJ ${ }^{*}{ }^{n} g r 3$ (API ${ }^{n} g r 3$, KAY $\eta r 3$, SUY ${ }^{n} g \lambda 3$, TAP ${ }^{n} g_{G 3}$, TIM $k r 3 /=\eta k r 3$ ), PCJ ${ }^{*} k r \varepsilon$ (XAV $2 r \varepsilon$, XER kre);

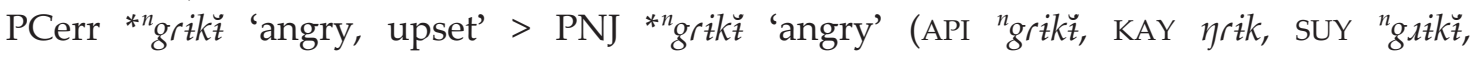
TIM $k r i k /=\eta k r i k$, PNR $\left.\tilde{\imath}^{n} k y i\right)$, PCJ *haka (XAV haka);

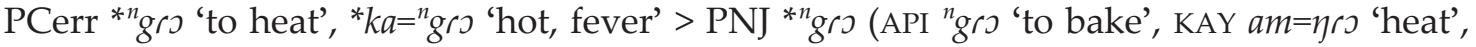

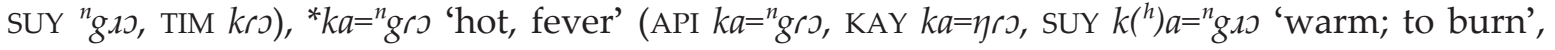

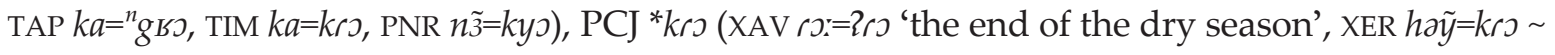
he $\tilde{y}=k r \supset$ 'to warm up by the fire'), *wa:=kro 'hot, fever' (XAV wa:=2ro, XER wa=kro);

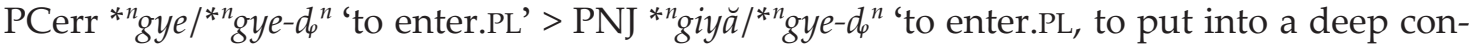

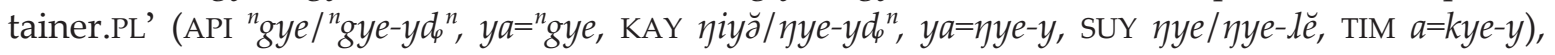
PCJ *3a/*3a-ci 'to enter.DU' (non-alternating 3) (XAV za/za-ci, XER za-si za-s);

PCerr * $k a$ 'white' > PNJ *ya=ka (API, KAY, SUY, TAP ya $a a$, TIM $\left.y a=k^{h} a\right)$, PCJ *ka (XAV $2 a$, XER $\left.k a\right)$;

PCerr *kan broy 'blood' > PNJ *kan bro 'blood, menstruation' (API kan bro, KAY kamro kamrõ,

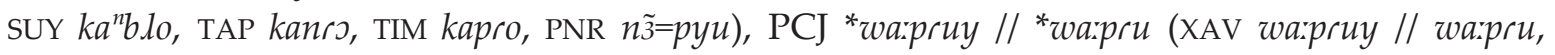
XER wapru);

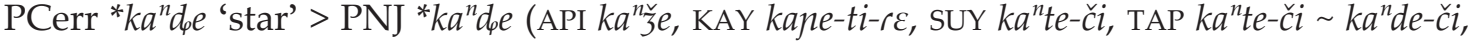

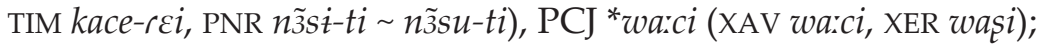

PCerr ${ }^{*} k a^{n} g a$ 'lazy' > PNJ ${ }^{*} k a^{n} g a{ }^{*}{ }^{*} u=k a^{n} g a$ 'lazy, to give up, to refuse' (API $k a^{n} g a$, KAY $k a \eta a$,

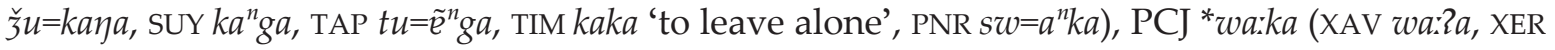
waka);

PCerr *kakă ‘to cough' > PNJ *kakĭ (API kakă, TIM k ${ }^{\text {hak}), ~ P C J ~ * k a k a ~(X A V ~ l a ? a, ~ X E R ~ k k a) ; ~}$

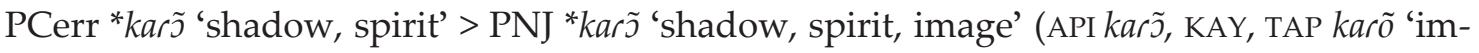

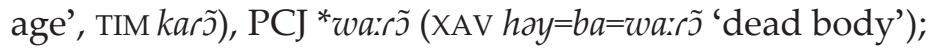


PCerr ${ }^{*} k a=t \supset /{ }^{*} k a=t \jmath-P r \breve{\jmath}$ 'to leave, to go out' > PNJ * $k a=t \jmath /{ }^{*} k a=t \jmath-r$ 'to leave, to go out, to appear, to be born' (API $k a=t \jmath / k a=t \jmath-r$, KAY $k a=t \jmath / k a=t \jmath-r \breve{\jmath}$, SUY $k a=t^{h} \jmath / k a=t^{h} \jmath-l \breve{\jmath}$, TAP $k a=t \jmath / k a=t \jmath-r \breve{\jmath}$,

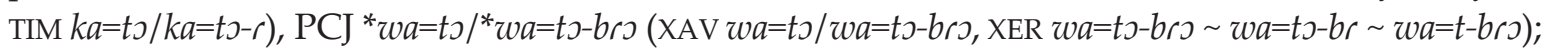

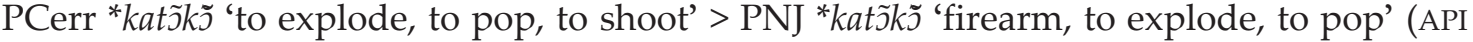

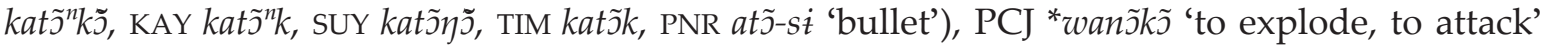
(XAV wañ̃ $\tilde{\jmath}$, XER wanõkõ);

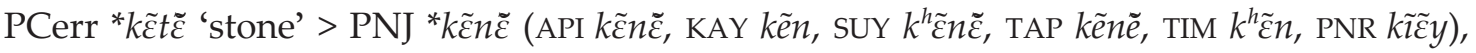
$\mathrm{PCJ}{ }^{*} k \tilde{\varepsilon} t \tilde{\varepsilon} / /{ }^{*} k \tilde{\varepsilon}: n \tilde{\varepsilon}(\mathrm{XAV}\{\tilde{\varepsilon} t \tilde{\varepsilon} / / 2 \tilde{\varepsilon}: n \tilde{\varepsilon}, \mathrm{XER} k t \tilde{e} / / k n \tilde{e}) ;$

PCerr ${ }^{*} k_{3} /{ }^{*} k_{3}-r$ 'to shout' > PNJ ${ }^{*} k_{3} /{ }^{*} k_{3}-r$ 'to sing (of birds)' (API $k_{3} / k_{3}-r, \mathrm{KAY} k_{3} / k_{3}-r \breve{3}$, TIM $k^{h} 3$ ), $\mathrm{PCJ} *$ ha/*ha-ra (XAV ha/ha-ra, XER ha/ha-ra ha-r h-ra);

PCerr * $k_{3} y$ 'skin, bark, breast' > PNJ *k3 (API, KAY k3, SUY $k^{h} 3$, TAP $k_{3}$, TIM $k^{h} 3$, PNR $k_{3}$ 'skin, bark'), PCJ *hay (XAV ha, XER hay he // ha 'body, skin, breast'), *hay-mãnã // *hay-ba 'being' (XAV haymãnã // hay-ba 'to be, to behave; being, body', XER hay-mba he-mba 'to exist; soul, body, image');

PCerr *ksykwa 'sky' > PNJ *kVykwa (API katkwa, KAY k3ykwa, TAP kaykwa, TIM koyk $k^{h} w a$ ), PCJ *haywa (XAV haywa, XER haywa hewa);

PCerr *kokŏ 'wind' > PNJ *kokŏ (API kokŏ, KAY kok, SUY kokŏ, TAP kogŏ, TIM khok), PCJ * $k^{*}=w a=k u k u$

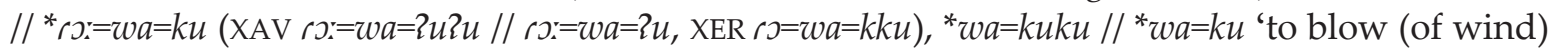
(XER $w a=k k u)$;

PCerr *komŏ 'cudgel; horn; patch of trees' > PNJ *ko (API ko 'cudgel; patch of trees', KAY ko

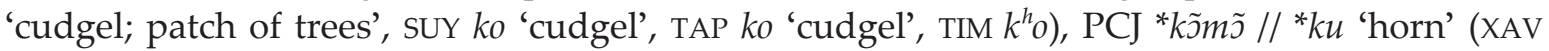

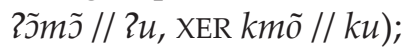

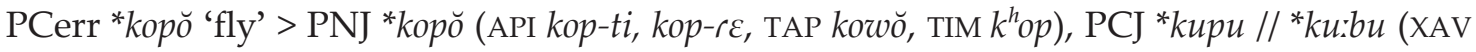

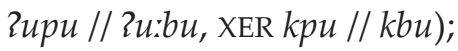

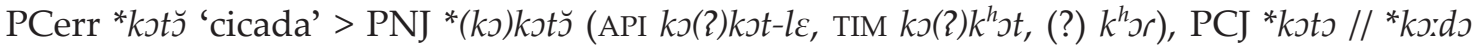
(XAV 2oto // 2o:do, XER kdo krdo);

PCerr *kra 'offspring' > PNJ *kra (API, KAY $k r a$, SUY $k\left({ }^{h}\right) r a$, TAP $k \chi a$, TIM $\left.k^{h} r a\right)$, PCJ ${ }^{*} k r a: / /{ }^{*} k r a$ (XAV 2ra: // 2ra, XER kra);

PCerr *krată 'base' > PNJ *kratŭ 'base, stem, beginning; lower part of the body' (API krată 'waist, leg, beginning, medial part of a long object', krayč 'wall, stem, stalk', KAY krayč 'trunk, stump, pelvis', SUY $k^{h} \lambda a r \breve{\imath}$ 'beginning', TIM $k^{h} r a t$, PNR kyat ginning; near; grandparent' (XAV 2rata // 2ra:da, XER krata // krda 'previous, old; near');

PCerr ${ }^{*} k r \varepsilon$ 'to plant' $>$ PNJ ${ }^{*} k r \varepsilon$ (API, KAY $k r \varepsilon$, SUY $k^{h} \lambda \varepsilon$, TIM $k^{h} r \varepsilon$ 'to dig, to plant', PNR $k r \varepsilon$ ), PCJ *kre (XAV 2re, XER kre);

PCerr ${ }^{*} k r \varepsilon$ 'orifice, hole' $>$ PNJ ${ }^{*} k r \varepsilon$ (API, KAY $k r \varepsilon$, TAP $k \chi \varepsilon$, TIM $k^{h} r \varepsilon$, PNR $k r \varepsilon$ ), PCJ ${ }^{*} a m=k r e$ 'hole, pit, tomb' (XAV ab=2re, XER ap=kre), *kre 'vagina, anus' (XAV 2re, XER kre 'vagina');

PCerr ${ }^{*} k r \tilde{\varepsilon}$ 'parakeet' $>$ PNJ ${ }^{*} k r \tilde{\varepsilon}$ (API $k r \tilde{\varepsilon}-t i, k r \tilde{\varepsilon}-r \varepsilon$, SUY $k \tilde{\varepsilon}$, TAP $k \chi \tilde{e}$, TIM $k^{h} r \tilde{\varepsilon}-r \varepsilon$ ), PCJ ${ }^{*} k r \tilde{\varepsilon}$ (XAV $2 r \tilde{\varepsilon}-r e$, XER krẽ);

PCerr ${ }^{*} k r \tilde{\varepsilon} /{ }^{*} k r \tilde{\varepsilon}-r \sim{ }^{*} k r \tilde{\varepsilon}-n \tilde{\varepsilon}$ 'to eat' > PNJ ${ }^{*} k r \tilde{\varepsilon} /{ }^{*} k r \tilde{\varepsilon}-r($ API $k r \tilde{\varepsilon} / k r \tilde{\varepsilon}-r$ 'to eat, to swallow', KAY $k r \tilde{e} /$ $k r \tilde{e}-n, \operatorname{SUY} k^{h} \lambda \tilde{\varepsilon} / k^{h} \lambda \tilde{\varepsilon}-n \tilde{\varepsilon}, \operatorname{TAP} k \chi \tilde{e} / k \tilde{e}-r \tilde{e}, \operatorname{TIM} k^{h} r \tilde{\varepsilon} / k^{h} r \tilde{\varepsilon}-r$, PNR $\left.k r \tilde{\varepsilon}\right), \operatorname{PCJ}{ }^{*} k r \tilde{\varepsilon} /{ }^{*} k r \tilde{\varepsilon}-n \tilde{\varepsilon}(X A V R r \tilde{\varepsilon} / 2 r \tilde{\varepsilon}-n \tilde{\varepsilon}$, XER $k r \tilde{e} / k r \tilde{e}-n \tilde{e})$;

PCerr ${ }^{*} k r \tilde{3}$ 'dark, cloud' > PNJ ${ }^{*} k r \tilde{3}$ (PNR $\left.r \tilde{3}=k y \tilde{3} / y a=k y \tilde{3}\right),{ }^{*} k a=k r \tilde{3}$ 'dark cloud' (API $k a \tilde{z}=k r \tilde{3}$,

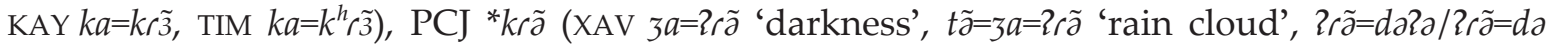
'black, dark', XER krã 'black (in compounds)', aynz̃ $=k a=k r \tilde{a}$ 'rain cloud');

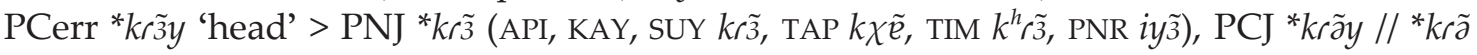
'head, fruit' (XAV 2rãy // 2rã, XER krãy // krã);

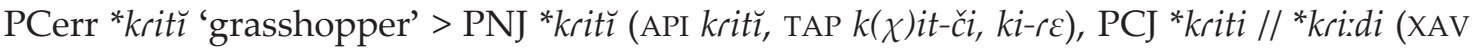
2riti // 2ri:di, XER krti // krdi 'grasshopper sp. (likely Tropidacris cristata)); 

XER ha);

PCerr ${ }^{*} k r i$ 'cold' > PNJ ${ }^{*} k r i$ (API, KAY $k r i$, SUY $k^{h} \lambda i$, TAP $k \chi i$, TIM $k^{h} r i$, PNR $\left.k y i\right)$, PCJ *ha (XAV,

PCerr * $k r i t u ̈$ 'flint, firestone; metal' > PNJ *kritü (API kritü 'flint; to attack', SUY kairü 'metal', kait-či 'ax', kait-twa 'fishhook', kait-ho 'big knife'), PCJ *hata // *ha:da (XAV hada-ra 'ax', XER hda);

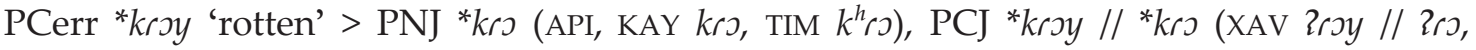
XER kroy // kro);

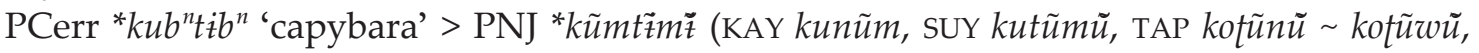
TIM kũmtũm, PNR intin), PCJ *kumda (XAV ?ubda, XER kumda);

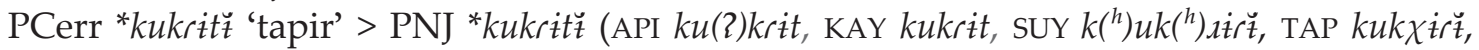

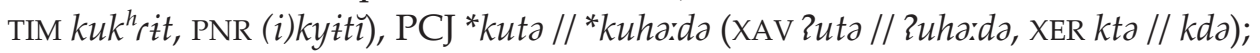

PCerr *kupe 'to touch, to move' > PNJ *kupe (API kupe/kupe-yd ${ }^{n}$, TIM kupe/kupe- $d^{n}$ 'to touch lightly; to reproach'), PCJ *kupi (XAV 2upi, XER kupi 'to touch');

PCerr *kupu 'to wrap' > PNJ *kupu (API, KAY, TIM kupu), PCJ *kubu 'to cover' (XAV ?ubu);

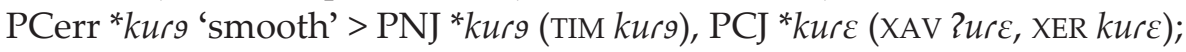

PCerr *kutimü 'fire' > PNJ *kuti (API kuvi, KAY kuwi, sUY kwisi, TAP kuti, TIM kuhi, PNR isi), PCJ *kunãmã // *kuзa (XAV \{unãmã // ใu३a, XER kunmã // kuza);

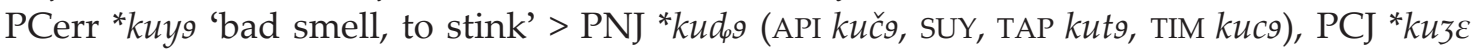
(XAV $2 u z \varepsilon$, XER $k u z \varepsilon)$;

PCerr ${ }^{*} k V y w a$ 'salt' > PNJ ${ }^{*} k a d_{\imath} w a$ (API kačwa, SUY $k^{h} a t w a$, TAP $k a t^{w} a$, TIM ka:cwa), PCJ *kVkwa((?) XAV そ̇iwa-wa:ha, XER kakwa-rã);

PCerr ${ }^{*} k w \tilde{z} /{ }^{*} k w \tilde{z}-r \sim{ }^{*} k w \tilde{z}-\mu$ 'to hit, to strike' $>$ PNJ ${ }^{*} k w \tilde{z} /{ }^{*} k w \tilde{z}-n \sim{ }^{*} k w \tilde{t}-r$ (API $k w \tilde{z} r \tilde{t}, a t=k w \tilde{t} r \tilde{t} \sim$ $a t=k w \tilde{z} / p i=k w \tilde{z}-y n$ 'to break long objects', SUY $k u=k w \tilde{t}$, TIM $k w \tilde{\imath} / k w \tilde{\imath}-n$, PNR $k w \tilde{z})$, PCJ ${ }^{*} k w \tilde{a} /{ }^{*} k w \tilde{a}-r \tilde{\imath}$

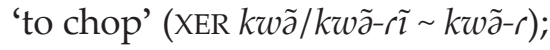

PCerr ${ }^{*} k y e /{ }^{*} k y e-d^{n}$ 'to drag, to pull' > PNJ ${ }^{*} k y e /{ }^{*} k y e-d^{n}$ (API kže/kže- $d^{n}$, KAY kye/kye- $d^{n}$, $\operatorname{TIM} k^{h} y e / k^{h} y e-d^{n}$, (?) PNR $\left.k r 3-r \grave{l}\right), \mathrm{PCJ}{ }^{*} c a /{ }^{*} c a-r i(X A V c a / c a-r i)$;

PCerr *kyey 'thigh' > PNJ *kye (API kže, KAY kye, TAP če, TIM $\left.k^{h} y e\right)$, PCJ *zay // *za (nonalternating *3) (XAV zay // za, XER zda);

PCerr ${ }^{*} m \tilde{\varepsilon} y$ 'to throw.SG' > PNJ ${ }^{*} m \tilde{\varepsilon} /{ }^{*} m \tilde{\varepsilon}-n$ (API $m \tilde{\varepsilon} / m \tilde{\varepsilon}-y n$, KAY $m \tilde{e} / m \tilde{e}-y n$, SUY $m \tilde{\varepsilon} / m \tilde{\varepsilon}-n \tilde{\imath}$, TAP $m \tilde{e} / m \tilde{e}-y$ 'to give, to throw', TIM $m \tilde{\varepsilon} / m \tilde{\varepsilon}-n), \operatorname{PCJ}{ }^{*} m \tilde{\varepsilon} y / /{ }^{*} m \tilde{\varepsilon}(\operatorname{XAV} m \tilde{\varepsilon} y / / m \tilde{\varepsilon}$, XER $m \tilde{e})$;

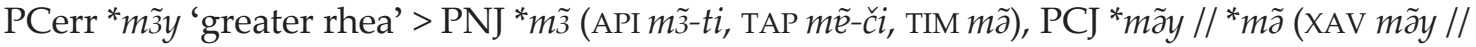
$m \tilde{\partial}$, XER $m \tilde{a})$;

PCerr * $m \tilde{\mathcal{\nu}} /{ }^{*} m \tilde{\mathcal{\nu}}-r$ 'to go/come' > PNJ * $m \tilde{\mathcal{\nu}} /{ }^{*} m \tilde{\mathcal{\nu}}-r$ (API $m \tilde{\mathcal{\nu}} / m \tilde{\mathcal{\nu}}-r$ 'to go/come.PL', KAY $m \tilde{o} / m \tilde{o}-r \tilde{o}$ 'to go/come.PL', SUY $m \tilde{\jmath} / m \tilde{\jmath}-l \tilde{\jmath}$ 'to go/come.PL', TAP $m \tilde{o} / m \tilde{o}-r \tilde{o}$ 'to go/come.PL', TIM $m \tilde{\jmath} / m \tilde{\jmath}-r$,

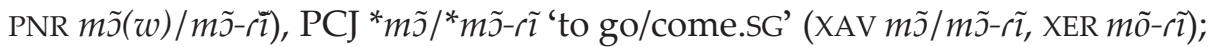

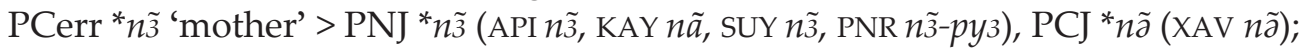

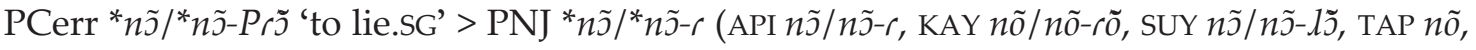

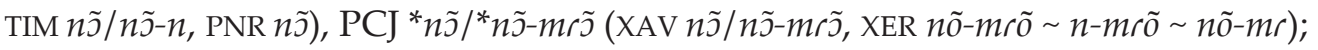

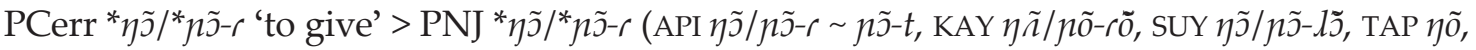

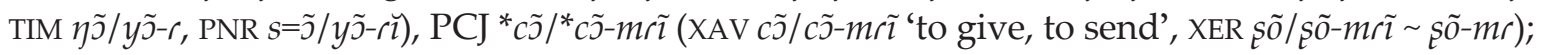

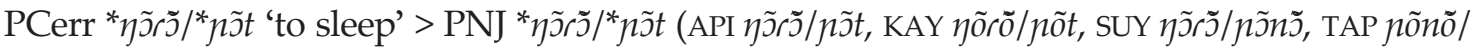

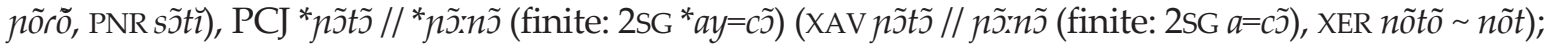

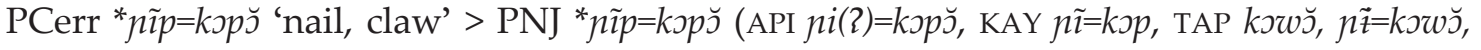

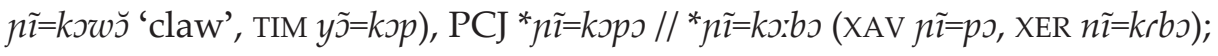

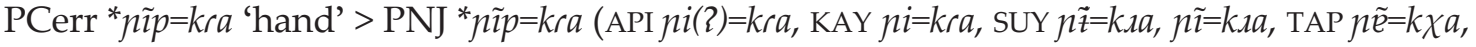
$\operatorname{TIM} y \tilde{\jmath}=k^{h} r a$, PNR $\left.y \tilde{\imath}=k y a\right)$, PCJ * $n \tilde{\imath} p=k r a(X \mathrm{AV}$ ni $p=k r a t a / /$ ji $p=k r a: d a$ (contamination with PCJ *krata // *kra:da 'stem, beginning'), XER nĩp=kra);

PCerr *nĩyi 'name' > PNJ *nĩdi (API niči, KAY niž i, sUY $n=i^{n} t i$, TAP ${ }^{n} t i \sim{ }^{n} t \tilde{i}={ }^{n} d i$, TIM yici, PNR

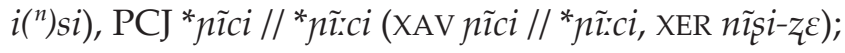




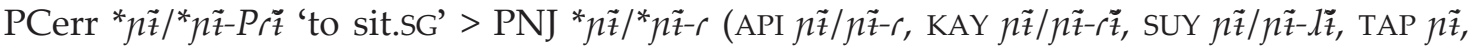

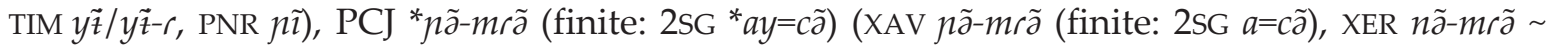
$n-m r \tilde{a}) ;$

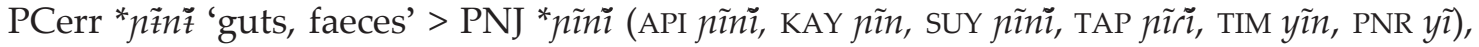
PCJ *nãnã (XAV ^ãnã, XER nnã);

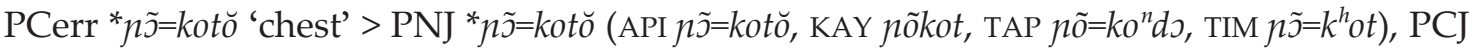
${ }^{*} n \tilde{\nu}=k u t u / /{ }^{*} n \tilde{\nu}=k u: d u(\operatorname{xAV} \eta \tilde{\nu}=2 u t u / / n \tilde{\nu}=2 u d u, \operatorname{xER} n \tilde{o}=k n \tilde{o}) ;$

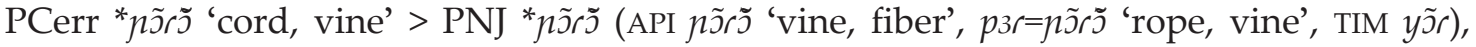

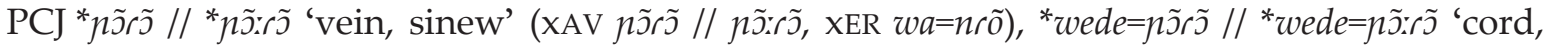

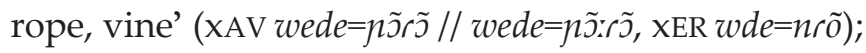

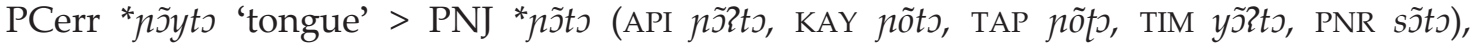
PCJ *ñ̃ytว (xAV hñyto ñ̃tto, xER nõyto);

PCerr * $p a$ 'arm, branch' > PNJ *pa (API, KAY pa, SUY hwa, TTAP $h^{w} a$, TIM, PNR pa), PCJ *pa-krata // *pa-kra:da (XER pa-krta //pa-krda), *wede=pa 'root' (XAV wede=pa, XER wde=pa), (?) *payñ̃ 'arm' (XAV pañ̃, xER paynõ);

PCerr ${ }^{*} p a /{ }^{*} p a-r$ 'to finish' > PNJ *pa/* pa-r 'to finish, cessative/completive marker' (API $p a /$ $p a-r$, KAY $p a$, SUY $h w a$, TAP $h^{w} a$, TIM $\left.p a-r\right)$, PCJ * $p a /{ }^{*} p a-r i$ 'to finish, to erase' (XAV pa/pa-ri, XER $p a /$ pa-ri pa-r);

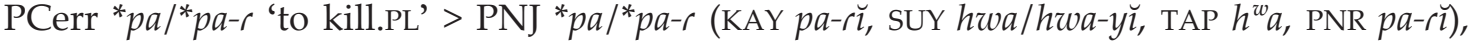

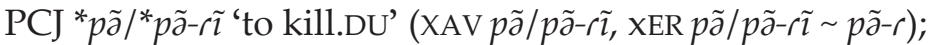

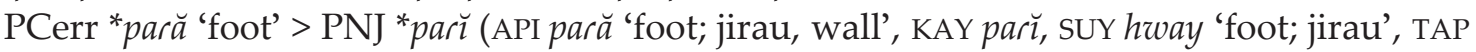
$h^{w} a y$ 'foot; bed', TIM par, PNR pa:), PCJ *para // *parca (XAV para // para, XER pra 'foot, footprint');

PCerr * $p e /{ }^{*} p e-r \sim{ }^{*} p e-k$ 'to fart' > PNJ *pe/*pe-k (API pe/pe-k, SUY hwe, TIM pe-k), PCJ *pi/*pi-ri (XAV pi/pi-ri);

PCerr *pĩmü 'firewood' > PNJ *pĩ 'wood' (API, KAY pĩ, SUY hwĩ 'tree', TAP $h^{w \tilde{\imath}}$ 'tree', TIM pĩ), PCJ *mĩmi // *mĩ (XAV mĩmĩ // mĩ, XER mmĩ);

PCerr * $p \dot{y}$ 'achiote' > PNJ *pi (API, KAY $p i$, TAP $h^{w} i$, TIM $\left.p i\right)$, PCJ *bay // *ba (XAV bay // ba, XER ba);

PCerr *piyi *pizyi 'one' > PNJ *pidei (API piči piči, KAY pǐ̌i, SUY, TAP witi, TIM pici-t, PNR

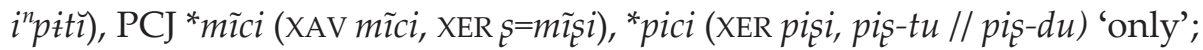

PCerr * $p$ 'flat, wide' > PNJ *po (API, KAY $p o$, SUY ho, TIM $p o$ ), PCJ *po (XER $p o$ );

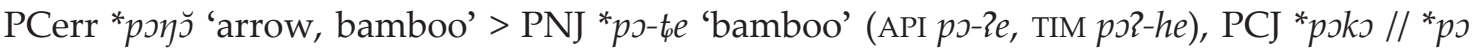
'big arrow' (XAV poks // po);

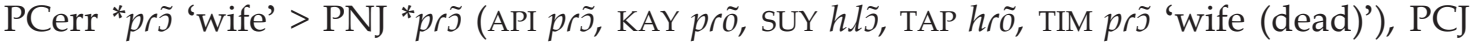
* $m r \tilde{\jmath}$ (XAV mrõ, XER mrõ 'spouse, to marry');

PCerr *pr3 'ember' > PNJ *prs (API pr3, KAY prs 'ashes', sUY hll 'ashes', TIM pr3, prsy-prsy 'coal'), PCJ *pre (XER pre-hika 'glowing embers', pre-nĩzuri 'spark', pre-zapdo 'ember');

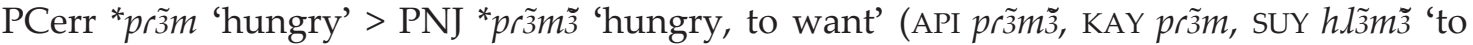

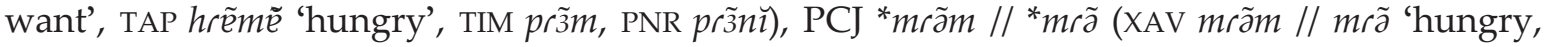
food', XER mrãm // mrã);

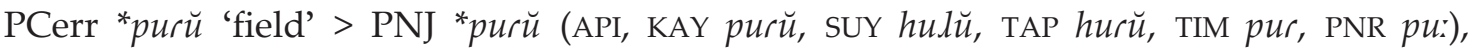
PCJ *buru // *burcu (XAV buru // bu:ru, XER bru);

PCerr ${ }^{*} r \varepsilon$ 'to leave' $>$ PNJ ${ }^{*} r \varepsilon /{ }^{*} r \varepsilon-r(\mathrm{API} r \varepsilon / r \varepsilon-r \sim r \varepsilon), \mathrm{PCJ}{ }^{*} r \tilde{\varepsilon} /{ }^{*} r \tilde{\varepsilon}-m \tilde{\varepsilon}$ 'to leave.SG' $\left(\mathrm{XAV} r \tilde{\varepsilon} /{ }^{*} r \tilde{\varepsilon}-m \tilde{\varepsilon}\right.$, XER $r \tilde{e} / r \tilde{e}-m \tilde{e} \sim r \tilde{e}-m \sim r-m \tilde{e})$;

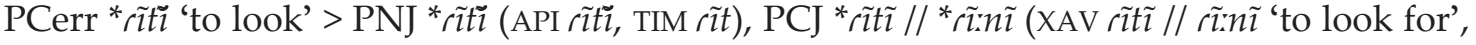
XER rĩtĩ $\sim r t i \tilde{i})$;

PCerr ${ }^{*} t a /{ }^{*} t a-d^{n}$ 'to tear' $>$ PNJ ${ }^{*} t a /{ }^{*} t a-d^{n}$ (API $t a$ 'to pick, to harvest', KAY ta 'to cut', SUY $k \lambda \tilde{e}=t a$ 'to cut', TAP $k \chi \tilde{e}=t a$ 'to cut with one cut', TIM $t a / t a-d^{n}$ 'to cut, to remove'), PCJ *ay=ta // *ta-ri (XAV $a=t a / t a-r i$ 'to get torn', XER ta-ri $\sim$ ta-r 'to pluck, to pick, to tear'); 

XER $t i)$;

PCerr ${ }^{*} t e$ 'tick' > PNJ ${ }^{*} t e$ (API te-ti, KAY te, TAP te, TIM ter-re, te--ti), PCJ *ti: // *ti (XAV ti--2a,

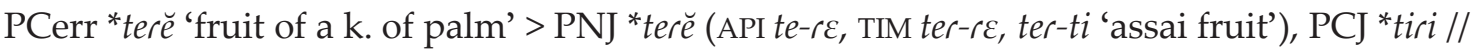
*ti:ri 'bacuri coconut' (XAV tiri // *tiri);

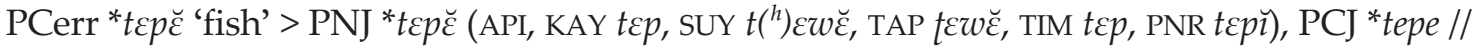
*te:be (XAV tepe // te:be, XER tpe // tbe);

PCerr ${ }^{*} t \varepsilon y$ 'leg' $>$ PNJ ${ }^{*} t \varepsilon$ (API, KAY $t \varepsilon$, SUY $t^{h} \varepsilon$, TAP $t \varepsilon$, TIM, PNR $t \varepsilon$ ), PCJ *tey // *te (XAV tey // te, XER te);

PCerr ${ }^{*} t \tilde{\varepsilon} /{ }^{*} t \tilde{\varepsilon}-m$ 'to go/come.SG' > PNJ ${ }^{*} t \tilde{\varepsilon} /{ }^{*} t \tilde{\varepsilon}-m\left(\mathrm{API} t \tilde{\varepsilon} / t \tilde{\varepsilon}-m, \mathrm{KAY} t \tilde{e} / t \tilde{e}-m, \operatorname{SUY} t\left({ }^{h}\right) \tilde{\varepsilon} / t\left({ }^{h}\right) \tilde{\varepsilon}-m \tilde{\varepsilon}\right.$,

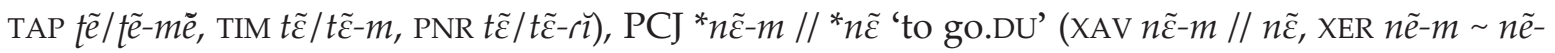
$m \tilde{a} / / n \tilde{e}) ;$

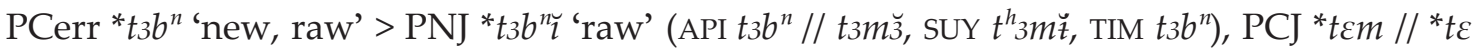
$(\mathrm{XAV} t \varepsilon m / / t \varepsilon)$;

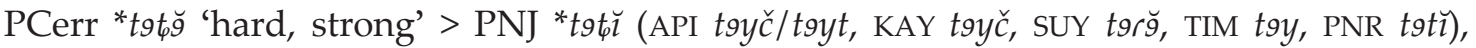
PCJ ${ }^{*}$ tete // te:de (XER tete $\sim$ tte $\sim$ tet), PCJ *nĩp=tete ${ }^{*}$ ap=tete // *nĩp=te:de/*ap=te:de 'to be strong' (XAV nĩ $=$ tete /ap=tete // nĩ =te:te/ap=te:te 'to get strong, to make an effort, to recover', XER nĩ $=$ tete $\sim$ nĩ $=$ tet $\sim$ nĩ $=$ tte // nĩ $=t d e)$;

PCerr *tikŭ 'belly' > PNJ *tikŭ (KAY tik, SUY $\left.t{ }^{h}\right) i k \breve{l}$, TIM tik 'pregnant'), PCJ *diki // ${ }^{*} d i($ XAV dizi $/ / d i$, XER $d k i / / d i$ 'belly; to fill the stomach');

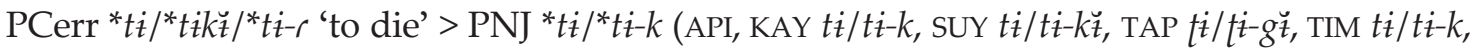
PNR ti), PCJ *dara // da/da-ra (XAV dara // da/da-ra, XER dka // da/da-ra);

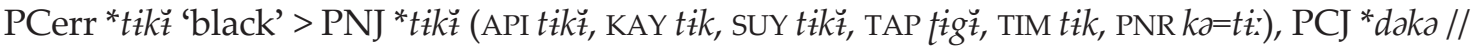
*da (XAV ?rõ $=d a$, XER $d k a$ 'dark', (?) $w a=k(r)=t \dot{i} / / w a=k(r)=d \dot{t})$;

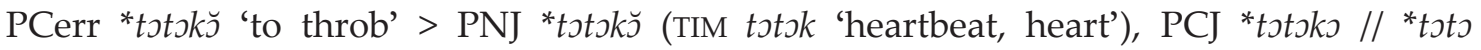
(XAV toto, XER totsko totko);

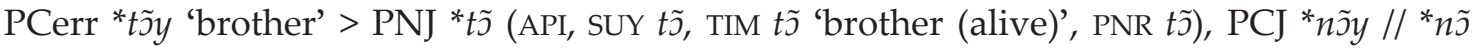

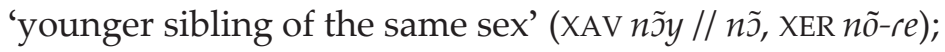

PCerr ${ }^{*} t u /{ }^{*} t u-r$ 'to carry' $>$ PNJ ${ }^{*} t u /{ }^{*} t u-r$ (API $t u$, KAY $t u / t u-r \breve{u}$, TIM $t u / t u-r$, PNR $t u-r \breve{\imath}$ 'to carry in a basket.SG'), PCJ *du // *du-ri 'to carry.SG' (XAV $d u / / d u-r i$, XER $d u / d u-r i \sim d u-r)$;

PCerr ${ }^{*} t u /{ }^{*} t u-r$ 'to urinate' $>$ PNJ ${ }^{*} t u /{ }^{*} t u-r$ (API $t u / t u-r$, SUY $\left.t u\right), \operatorname{PCJ}{ }^{*} t \tilde{\jmath} /{ }^{*} t \tilde{\jmath}-r \tilde{\imath}(\operatorname{XAV} t \tilde{\jmath} / t \tilde{\jmath}-r \tilde{\imath}$, XER t̃̃-rĩ);

PCerr *tub 'old, tall (?)' > PNJ *tũmũ 'old' (API tũmü, KAY tũm, SUY tũmũ, TAP tũmũ, TIM tũm,

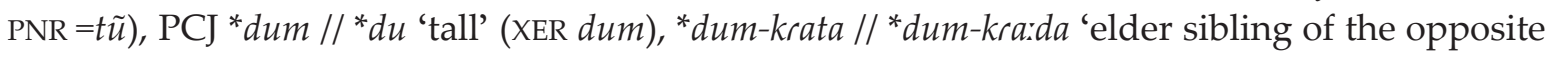
sex' (dub-2rata // dub-2ra:da, XER dum-krda);

PCerr *tumŭ 'belly' > PNJ *tu (API $t u$ 'belly, intestine', KAY $t u$, TAP $t u$, TIM, PNR $t u$, $i=t u$ 'tu-

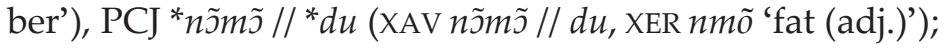

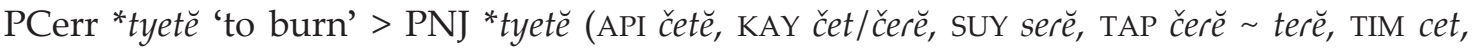
PNR titī), PCJ *3ata // *3a:da (XAV zata // za:da, XER zata);

PCerr * $t i$ 'bone' > PNJ *ti (API $i \sim \check{z} i$, KAY $2 i$, SUY si, TAP $t i$, TIM hi, PNR $s i)$, PCJ *hi (XAV, XER hi);

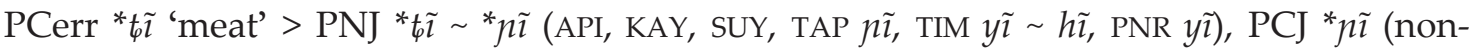
alternating $\left.{ }^{*} \eta\right)($ XAV $n \tilde{\imath}$, XER $n \tilde{\imath})$;

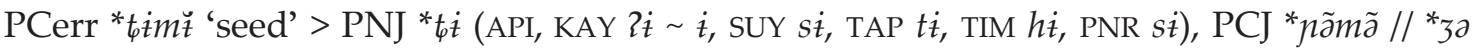
(XAV nãmã // za, XER za);

PCerr ${ }^{*} t_{0} y$ 'leaf' $>$ PNJ ${ }^{*} t_{0}$ (API $20 \sim 0$, KAY $\left\{0\right.$, SUY $h w \tilde{\imath}=s o$, TAP to $\sim h^{w} \tilde{\imath}=t o$, TIM ho 'leaf, a hair', PNR pari=s'o), PCJ * cuy // * cu (XAV we=cuy-rã, $=c u y / /=c u$, XER su 'a hair');

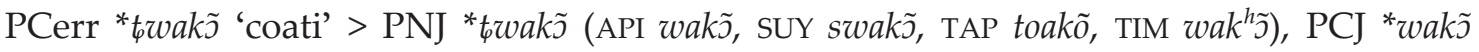
(XAV wå̃̃, XER wakõ); 
PCerr *weke 'partridge' > PNJ *beke (TIM pek ${ }^{h}$ ), PCJ *wiki (XAV wizi, XER wiki wiki);

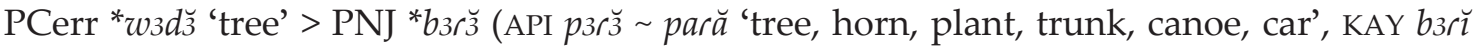

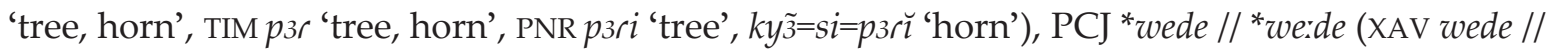
*we:de, XER wde);

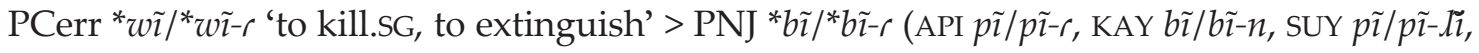

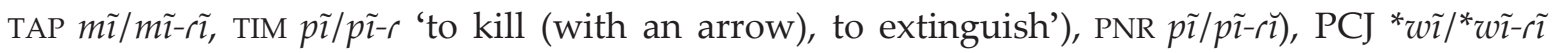
$(\operatorname{XAV} w \tilde{\imath} / w \tilde{\imath}-r \tilde{\imath}$, XER $w \tilde{\imath} / w \tilde{\imath}-r \tilde{\imath} \sim w-r \tilde{\imath})$;

PCerr *ya 'to stand.sG' > PNJ ${ }^{*} d_{\phi} a /{ }^{*} d_{p} 3-b^{n} \sim{ }^{*} d_{\phi} \tilde{a}-m$ (API $\check{c} a / \check{c} z-b^{n} \sim \check{c} a-r$, KAY $\check{z} a / \check{a} \tilde{a}-m$, SUY $t a / t \tilde{a}-m \ddot{a}$, TAP ta, TIM $c a / c a-b^{n} \sim c 3-b^{n} \sim c a-r$, PNR $\left.s \tilde{3} \sim s a: \eta\right)$, PCJ $3 a($ XAV $3 a$, XER $d a)$;

PCerr * yad-kwa 'mouth'> PNJ * yar-kwa (API ya-kwa, KAY, SUY yay-kwa, TAP yay-k ${ }^{w} a$, TIM yar-k $k^{w} a$, PNR sa-koa), PCJ *zada-wa (XAV zadawa, XER zdawa 'mouth, door');

PCerr *yate 'nest' > PNJ *yate (API, KAY yae, TIM ya:he, PNR sase), PCJ *zaci (XAV zaci, XER saşi 'to make a nest');

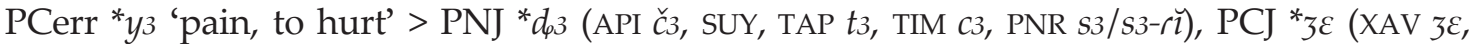
XER $z \varepsilon)$;

PCerr * $y_{3}$ 'urine' > PNJ *d, 'urine, bladder' (API čz, TIM c3), PCJ * $3 \varepsilon$ (XAV $z \varepsilon, z \varepsilon-k r e$ 'bladder', XER $z \varepsilon$ 'bladder');

PCerr ${ }^{*}=y 3$ (instrumental suffix $)>\mathrm{PNJ}{ }^{*}=d_{43}(\mathrm{API}=\check{c} 3, \mathrm{KAY}=\breve{3} 3, \mathrm{SUY}, \mathrm{TAP}=t 3, \mathrm{TIM}=c 3), \mathrm{PCJ}{ }^{*}=3 \varepsilon$ $(\mathrm{XAV}=3 \varepsilon, \mathrm{XER}=z \varepsilon)$;

PCerr ${ }^{*} y_{3} /{ }^{*} y_{3}-P r \breve{z}$ 'to enter.SG' > PNJ ${ }^{*} d_{\phi_{3}} /{ }^{*} d_{\phi_{3}}-r$ (API $a=\check{c}_{3} / \check{c} z-r$, KAY $w a=\bar{z} 3 / w a=\check{z} 3-r \breve{3}$, SUY $\left.a=t_{3} / t_{3}=t_{3}, \mathrm{TIM} c_{3} / c_{3}-r, \mathrm{PNR} s 3\right), \mathrm{PCJ}{ }^{*} 3 \varepsilon /{ }^{*} 3 \varepsilon-b r \varepsilon\left(\mathrm{XAV} 3 \varepsilon / 3 \varepsilon-b r \varepsilon, \mathrm{XER} z \varepsilon-b r \varepsilon \sim z_{-}-b r \varepsilon \sim d \varepsilon-b r \varepsilon\right)$;

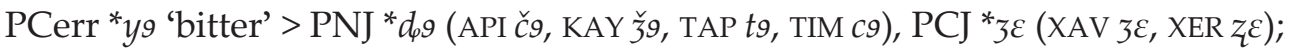

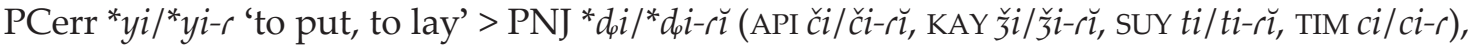
PCJ *hil*hi-ri 'to put.SG' (XAV hi/hi-ri 'to put, to leave.SG', XER hi/hi-ri 'to put, to cook, to determine.SG');

PCerr * $y o b^{n}$ 'to grind' > PNJ *dob $0 b^{n}$ 'flour, powder' (API čob // čomŏ, KAY $\breve{3} o b^{n}$, (?) TAP to=tom-či, $\left.\operatorname{TIM} \operatorname{cob}^{n}\right), \mathrm{PCJ}{ }^{*} \mathrm{CUm} / /{ }^{*} \mathrm{CU}(\mathrm{XAV} s u$, XER sum $\sim$ sumã // su);

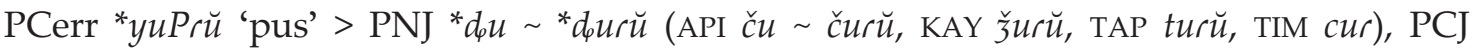
*3ubruy (XAV zubruy // zubru, XER zbruy // zbru);

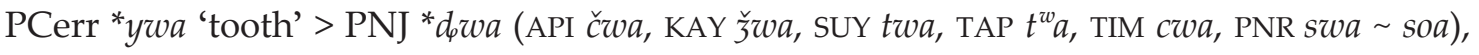
PCJ *kwa (XAV $2 w a$, XER kwa).

A non-exhaustive list of grammatical morphemes includes:

PCerr * $w a$ 'I (nominative)' > PNJ *ba (API $w a$, KAY $b a$, SUY $w a / p a$, TAP $w a$, TIM $w a / p a)$, PCJ * $w a$ (XAV wa-hã, XER wa, wa-hã);

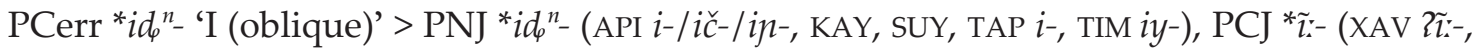
XER $\left.\tilde{\imath}^{-}\right)$;

PCerr * $g a$ 'thou (nominative)' > PNJ * $g a$ (API $k a$, KAY $g a$, SUY, TAP, TIM, PNR $k a$ ), PCJ *ka (XAV $2 a-h \tilde{a}$, XER $k a, t o=k a)$;

PCerr *ay- 'thou (oblique, class I)' > PNJ *a- (API, KAY, SUY, TAP, TIM $a-$, PNR $a-\sim h a-$ ), PCJ *ay (XAV ?ay-, XER ay-);

PCerr * $m \tilde{3}$ 'dative postposition' > PNJ ${ }^{*} m \tilde{3}$ (API, KAY, SUY, TAP, TIM, PNR $\left.m \tilde{3}\right)$, PCJ * $m \tilde{a}(\mathrm{XAV}$, XER $m \tilde{a})$;

PCerr *nimm 'genitive postposition' > PNJ * nĩm (PNR yĩ), PCJ *nĩm (XAV nĩm, XER nĩm);

PCerr ${ }^{*} t \varepsilon$ 'ergative postposition' $>\mathrm{PNJ}{ }^{*}=t \varepsilon$ (API, KAY, SUY $\left.=t \varepsilon, \mathrm{TAP}=r \varepsilon, \mathrm{TIM}=t \varepsilon\right), \mathrm{PCJ}{ }^{*} t e$ $(\mathrm{XAV}=t e, \mathrm{XER}=t e)$. 
The following comparisons are somewhat problematic:

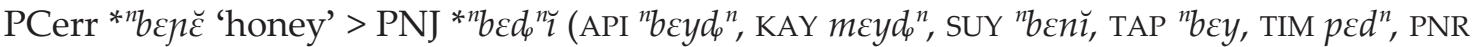
$n \tilde{a}=p \varepsilon y \eta), \operatorname{PCJ}{ }^{*} p \tilde{\imath} \tilde{\imath} / p \tilde{\imath}(\operatorname{XAV} p \tilde{\imath} n \tilde{\imath} / p \tilde{\imath})^{24}$;

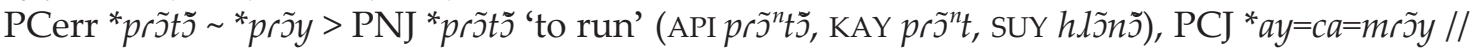
* $a y=c a=m r \tilde{\jmath}$ 'to run.DU' (XAV $a=c a=m r \tilde{\jmath} y / / a=c a=m r \tilde{s})$;

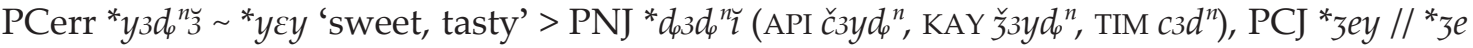
(XAV zey // ze, (?) XER zẽ̃).

\section{Conclusion}

In this paper I have undertaken the first attempt at a systematic reconstruction of ProtoCerrado phonology and lexicon. However, a number of issues remain to be tackled. These include:

- evolution of Central Jê verbal morphology and morphosyntax with a special attention to finiteness, verbal number and alignment;

- identification of the remaining correspondences between Proto-Northern Jê and ProtoCentral Jê, particularly involving diphthongs and codas;

- emergence of unexpected nasality in certain Central Jê roots;

- the origin of Central Jê stems belonging to the classes A and C.

Yet another issue that remains beyond the scope of this paper are contacts between Central Jê languages and Northern Jê languages. In addition to evident Central Jê borrowings in individual Northern Jê languages (Xavánte ?utə // Zuhə:də 'tapir' > Tapayúna uhə-či uhz-či, Central Jê *bata // *ba:da or Xavánte bata // ba:da ‘sun' > Panará wata-ti25), a number of roots reconstructible to Proto-Northern Jê and to Proto-Central Jê display completely irregular sound correspondences, suggestive of their loan origin in one of the branches (or in both), cf. 'southern tamandua' (PNJ "p3tз̆, PCJ *pati // "pa:di) ${ }^{* 6}$, 'paca' (PNJ *ngra, PCJ *krawa), 'tobacco'

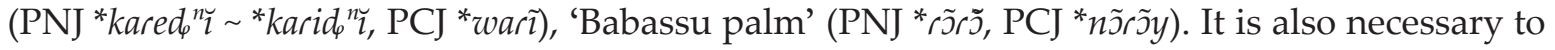
mention the curious case of the "Menren" 27 wordlist provided by Loukotka (1963: 51-54), which represents a Timbira variety close to Pykobjê (as suggested by its vocalism) and contains a considerable number of word of obvious Central Jê origin (Nikulin 2015: 26-27).

According to the principles of bottom-up reconstruction, a reconstruction of Proto-Jê is necessary in order to warrant a coherent use of Jê data in Macro-Jê comparative studies. I intend to proceed to this stage in a future paper.

\section{References}

Albuquerque, Francisco Edviges. 2011. Gramática pedagógica da língua Apinajé. Goiânia, GO: Editora da PUC Goiás. Albuquerque, Francisco Edviges (org.). 2012. Dicionário Escolar Apinayé. Panhĩ Kapẽr - Kupẽ kapẽr. Apinayé Português. Belo Horizonte, MG: Editora da Faculdade de Letras - UFMG.

${ }^{24}$ If Xavánte pĩn $/ /$ pi is a result of leveling of PCJ * piñ // *pi, it may be compared to Xerénte $p i$ (as in $t \supset=p i$ 'eye rheum'), Proto-Southern Jê *nbe 'liquid', Rikbáktsa pi-hik, Karajá be, Proto-Jabutí *nbi 'water'. In this case, ProtoCerrado *nbene should be reconstructed, and the etymology of PNJ ${ }^{* n} b \varepsilon d_{\phi}^{n} \iota$ has to be viewed as unknown.

${ }_{25}$ This etymology has been suggested by Carvalho (2016: 71-72). A native synonym, $i^{n} p i t \breve{l}$, also exists in Panará; this item is a true cognate of PCJ *bata // *ba:da.

${ }^{26}$ As Ribeiro and Voort (2010: 557) point out, vaguely similar words exist in Karajá, Jabutí, Tupí and Karíb languages, which suggests that this item might by a Wanderwort.

${ }^{27}$ A mistranscription of $m \tilde{e}=h \tilde{e}$ 'Indians', lit. 'our meat'. 
Barbosa, Alexandre de Sousa. 1918. Cayapó e panará. Manuscript. Available online at <http://etnolinguistica.wdfiles. com/local--files/biblio\%3Abarbosa-1918-cayapo/barbosa_1918_cayapo.pdf>.

Bardagil-Mas, Bernat. 2016. Negation mechanisms in Panará (Jê). Amazónicas VI. Coloquio Internacional AMAZÓNICAS ("La estructura de las lenguas amazónicas”) (abstract book), pp. 70-71. Leticia/Tabatinga: Universidad Nacional de Colombia; Universidade do Estado do Amazonas; Instituto Caro y Cuervo.

Braggio, Silvia Lucia Bigonjal. 2004. Revisitando a fonética/fonologia da língua Xerente Akwẽ: uma visão comparativa dos dados de Martius (1866), a Maybury-Lewis (1965) com os de Braggio (2004). Signótica 17(2): 251-274.

Burgess, Eunice. 1971. Duas análises das sílabas do xavánte. In: Sarah C. Gudschinsky (ed.). Estudos sôbre línguas e culturas indígenas, pp. 96-102. Brasília: Summer Institute of Linguistics.

Camargo, Nayara da Silva. 2010. Língua Tapayúna: aspectos sociolingüísticos e uma análise fonológica preliminar. MA thesis. Campinas: Universidade Estadual de Campinas.

Camargo, Nayara da Silva. 2015. Tapayuna (Jê): aspectos morfossintáticos, históricos e sociolinguísticos. PhD. Campinas: Universidade Estadual de Campinas.

Carvalho, Fernando O. de. 2016. On the Development of the Proto-Northern Jê Rhotic in Panará Historical Phonology. Anthropological Linguistics 58(1): 52-78.

Carvalho, Fernando O. de, Gean Nunes Damulakis. 2015. The structure of Akroá and Xakriabá and their relation to Xavante and Xerente: A contribution to the historical linguistics of the Jê languages. Linguas Indígenas Americanas 15(1): 17-46.

Castro Alves, Flávia de. 1999. Aspectos fonológicos do Apãniekrá (Jê). MA thesis. São Paulo: Universidade de São Paulo.

Cotrim, Rodrigo Guimarães Prudente Marquez. 2016. Uma descrição da morfologia e de aspectos morfossintáticos da língua Akwẽ-Xerente (Jê Central). PhD. Brasília: Universidade de Brasília.

D’Angelis, Wilmar da Rocha. 1998. Traços de modo e modos de traçar geometrias: línguas Macro-Jê E teoria fonológica. PhD. Campinas: Universidade Estadual de Campinas.

Damulakis, Gean Nunes. 2010. Fonologias de línguas Macro-Jê: uma análise comparativa via teoria da otimalidade. PhD. Rio de Janeiro: Universidade Federal do Rio de Janeiro.

Davis, Irvine. 1966. Comparative Jê phonology. Estudos Lingüísticos: Revista Brasileira de Lingüística Teórica e Aplicada 1(2): 20-24.

DMK = Dicionário Multimídia Kĩsêdjê. Online resource. Available online at <http://prodoclin.museudoindio.gov.br/ index.php/etnias/kisedje/dicionario-multimidia>.

Ehrenreich, Paul. 1895. Materialien zur Sprachenkunde Brasiliens: III. Die Sprache der Akuä oder Chavantes und Cherentes (Goyaz). Zeitschrift für Ethnologie 27: 149-162.

Estevam, Adriana Machado. 2011. Morphosyntaxe du xavante. Langue jê du Mato Grosso (Brésil). PhD. Paris: Université Paris Diderot (Paris 7).

Frazão, Kêt Simas. 2013. A sílaba no Akwẽ-Xerente (Jê). MA thesis. Brasília: Universidade de Brasília.

Hall, Joan, Ruth Alice McLeod, Valerie Mitchell. 1987 [2004]. Pequeno dicionário Xavante-Português, PortuguêsXavante. Damreme pibuzé hã a'uwẽ mreme, warazu mreme na te te ĩsaprĩ mono zém na duré warazu mreme, a'uwẽ mreme na te te ĩsaprĩ mono zém na. Cuiabá: Sociedade Internacional de Lingüística.

Ham, Patricia. 1961. Apinayé Grammar. Arquivo Linguístico, n. 108. Brasília: Summer Institute of Linguistics.

Krieger, Wanda Braidotti, Guenther Carlos Krieger (orgs.). 1994. Dicionário escolar: Xerente-Português; PortuguêsXerente. Rio de Janeiro: Junta das Missões Nacionais da Convenção Batista Brasileira.

Lapierre, Myriam, Bernat Bardagil-Mas, Andrés Pablo Salanova. 2016a. The nasal consonants of Panará. A talk given at the 21st Workshop on the Structure and Constituency of Languages of the Americas. Montréal: Université du Québec à Montréal.

Lapierre, Myriam, Andrés Salanova, Bernat Bardagil-Mas. 2016b. A reconstruction of Proto-Northern Jê phonemics. Amazónicas VI. Coloquio Internacional AMAZÓNICAS (“La estructura de las lenguas amazónicas”) (abstract book), pp. 110-111. Leticia/Tabatinga: Universidad Nacional de Colombia; Universidade do Estado do Amazonas; Instituto Caro y Cuervo.

Lapierre, Myriam. 2017. Post-oralized and devoiced nasals in Panará. A talk given at the Symposium on Amazonian Languages II (April 8, 2017). Berkeley: University of California.

Loukotka, Čestmír. 1963. Documents et vocabulaires inédits de langues et de dialectes sud-américains. Journal de la Société des Américanistes 52: 7-60. 
Martius, Carl Friedrich von. 1867. Beiträge zur Ethnographie und Sprachenkunde Amerikas zumal Brasiliens. I. Zur Ethnographie. II. Glossaria linguarum Brasiliensium. Leipzig: Friedrich Fleischer.

Mattos, Rinaldo de. 1973. Fonêmica Xerente. Série Lingüística 1: 79-100.

McLeod, Ruth. 1974. Fonemas xavánte. Série Lingüística 3: 131-152.

McLeod, Ruth, Valerie Mitchell. 1977 [2003]. Aspectos da lingua xavante. Cuiabá: Sociedade Internacional de Lingüística.

Nikulin, Andrey. 2015. Verifikaciya gipotezy o zhe-tupi-karibskom rodstve [On the genetic unity of Jê-Tupí-Karib]. MA thesis. Moscow: Moskovskiy gosudarstvennyy universitet imeni M. V. Lomonosova.

Nikulin, Andrey. 2016a. Proto-Jê revisited: phonology, morphophonology and language contact. Amazónicas VI. Coloquio Internacional AMAZÓNICAS (“La estructura de las lenguas amazónicas”) (abstract book), pp. 108-109. Leticia/Tabatinga: Universidad Nacional de Colombia; Universidade do Estado do Amazonas; Instituto Caro y Cuervo.

Nikulin, Andrey. 2016b. Historical phonology of Proto-Northern Jê. Journal of Language Relationship 14(3): 165-185.

Nikulin, Andrey, Fernando O. de Carvalho. 2017. Prehistoria de las lenguas y familias lingüísticas del Gran Chaco, de la meseta brasileña y cercanías: Propuesta de base de datos léxicos y resultados preliminares. IV Encuentro de lenguas indígenas americanas (abstract book), pp. 37-38. Santa Rosa: Universidad Nacional de La Pampa.

Oliveira, Christiane Cunha de. 2005. The language of the Apinajé people of Central Brazil. PhD. Eugene: University of Oregon.

Oliveira, Christiane Cunha de, Eduardo Rivail Ribeiro. 2005. Vowel shift in Central Jê. A talk given at the XVII International Conference on Historical Linguistics. Madison: University of Wisconsin.

Pessoa, Katia Nepomuceno. 2012. Análise fonética e fonológica da língua Krenak e abordagem preliminar de contos Botocudo. PhD. Campinas: Universidade Estadual de Campinas.

Pickering, William Alfred. 2010. A fonologia xavante: uma revisitação. PhD. Campinas: Universidade Estadual de Campinas.

Popjes, Jack, Josephine Popjes. 1971 [2009]. Phonemic Statement of Canela. Anápolis, GO: Associação Internacional de Linguística, SIL - Brasil.

Quintino, Wellington Pedrosa. 2000. Aspectos da fonologia xavante. MA thesis. Campinas: Universidade Estadual de Campinas.

Quintino, Wellington Pedrosa. 2012. Aspectos da fonologia xavante e questões relacionadas: rinoglotofilia e nasalidade. PhD. Rio de Janeiro: Universidade Federal do Rio de Janeiro.

Ramirez, Henri, Valdir Vegini, Maria Cristina Victorino de França. 2015. Koropó, puri, kamakã e outras línguas do Leste brasileiro: revisão e proposta de nova classificação. Linguas Indígenas Americanas 15(2): 223-277.

Ribeiro, Eduardo Rivail, Hein van der Voort. 2010. Nimuendajú was right: The inclusion of the Jabutí language family in the Macro-Jê stock. International Journal of American Linguistics 76: 517-570.

Ribeiro, Rosa Maria de Lima. Dicionário Arikapu-Português: registro de uma língua indígena amazônica. MA thesis. Guajará-Mirim: Universidade Federal de Rondônia, Campus de Guajará-Mirim.

Rodrigues, Aryon Dall'Igna. 1999. Macro-Jê. In: Dixon, R. M. W., Alexandra Y. Aikhenvald (eds.). The Amazonian Languages, pp. 165-206. Cambridge: Cambridge University Press.

Rodrigues, Aryon Dall'Igna. 2004. Sobre a possível diferença fonética entre a fala masculina e feminina em Karajá. Linguas Indígenas Americanas 4: 115-122.

Rodrigues, Aryon Dall'Igna. 2012. Flexão relacional no tronco linguístico Macro-Jê. Revista Brasileira de Linguística Antropológica 4(2): 267-277.

Silva, Talita Rodrigues da. 2011. Descrição e análise morfossintática do nome e do verbo em Pykobjê-Gavião (Timbira). MA thesis. São Paulo: Universidade de São Paulo.

Silva, Talita Rodrigues da. 2012. Análise sobre a tipologia da ordem dos constituintes do dialeto indígena PykobjêGavião (Timbira). Estudos Linguísticos 41(1): 231-245.

Salanova, Andrés Pablo. A flexão de terceira pessoa nas línguas Jê. Línguas Indígenas Americanas 11: 75-114.

Siqueira, Kênia Mara de Freitas. Aspectos do substantivo na língua Xerente. MA thesis. Goiânia: Universidade Federal de Goiás.

Sousa Filho, Sinval Martins. 2007. Aspectos Morfossintáticos da Lingua Akwẽ-Xerente (Jê). PhD. Goiânia: Universidade Federal de Goiás.

Souza, Shelton Lima de. 2008. Descrição fonético-fonológica da língua akwen-xerente. 2008. MA thesis. Brasília: Universidade de Brasília. 
Vasconcelos, Eduardo Alves. 2013. Investigando a hipótese Cayapó do Sul-Panará. PhD. Campinas: Universidade Estadual de Campinas.

Vasilyev, Mikhail, Mikhail Saenko. K voprosu o tochnosti glottoxronologii: datirovanie jazykovoj divergencii po dannym romanskix jazykov. [How accurate can glottochronology be? Dating language divergence on the basis of Romance data.] Journal of Language Relationship 15(2): 114-135.

Voort, Hein van der. 2007. Proto-Jabutí: um primeiro passo na reconstrução da língua ancestral dos Arikapú e Djeoromitxí. Boletim do Museu Paraense Emílio Goeldi. Ciências Humanas 2(2): 133-168.

\section{А. В. Никулин. Реконструкция фонологии праязыка нагорной ветви семьи же}

Статья продолжает серию публикаций по исторической фонологии языков южноамериканской макросемьи макро-же. Автор устанавливает систему регулярных фонетических соответствий между языками центральной группы семьи же (шаванте и шеренте) и предлагает на их основе реконструкцию праязыка этой группы. Затем эта реконструкция сопоставляется с реконструкцией праязыка северной группы семьи же (Nikulin 2016b), и предлагается реконструкция общего праязыка для этих двух групп, пранагорного же. В статье приводится не претендующий на полноту список этимологий для нагорной ветви семьи же.

Ключевые слова: языки же, языки макро-же, язык шаванте, язык шеренте, языковая реконструкция, сравнительно-исторический метод. 